\title{
Developing the Relationship Management Upper Mid-Range Theory
}

Placing the envisioned RM mid-range theory under the umbrella of Resource-Advantage Theory of Competition (R-A theory) requires incorporating some of its basic micro-economical premises, which constitute the general boundaries of RM-based competitive advantage programmatic research. These have been discussed throughout this book; however, at this juncture, bringing them together will help to clearly mark the area where R-A theory ends and the RM upper mid-range theory should begin.

A theory of competitive advantage at the microeconomic level should foremostly explain the diversity of firms and the differences in their performance. R-A theory does this by articulating the heterogeneity and instability of markets, which implies the possibility for firms in the same industry to supply them differently (Hunt and Morgan 1996). This dual specificity of individual and institutional clients' needs, preferences and tastes even within a generic offer class, and of the varied ways companies cater to these needs, preferences and tastes, implies that there can be better and worse matches of what clients expect and of what is delivered.

In terms of clients' needs, R-A theory emphasizes imperfect information about the offerings available in the market and that the information search involves costs (at least the cost of time). In addition, R-A theory opposes the 'homo economicus' view of human choices (as consumers, employees and managers) as these choices are not only motivated by

(C) The Author(s) 2021

B. Deszczyński, Firm Competitive Advantage Through Relationship Management, https://doi.org/10.1007/978-3-030-67338-3_5 
self-interest (that can be reduced to pleasure), but also by moral choices (doing not only what is allowed by what is right, ethical; Hunt and Morgan 1995).

Based on the premise that companies are expected to generate profits and that worse matches between customer expectations and firms' offerings generate reduced or zero profits, R-A theory insists that worse performing companies are also worse equipped with the resources needed to achieve better matches. Given the endless diversity of possible resource bundles, the main task of management is to decide on resource configurations that will bring the company a competitive advantage now and in the future. Hence, firms also differ in their strategy choices, which are influenced but not caused by the external environment (Hunt and Morgan 2005).

Following RBV, R-A theory distinguishes between tangible and intangible resources, including relational capital. Further on, it acknowledges that relationships are not owned, but only temporarily co-shared by firms. Lastly, R-A theory emphasizes that, given the importance of relationships but also their varying quality, companies should develop and manage a relationship portfolio (Hunt 1997). However, it does not give instructions as to how to do this. This is exactly the point where the RM upper mid-range theory takes the baton.

The central challenge for the RM upper mid-range theory is to propose a relational response to the question that lies at the heart of the strategic management research agenda (Rumelt et al. 1995): how companies achieve and sustain competitive advantage. Obviously, the final proposal of the RM maturity model will be very helpful in providing this answer. However, the epistemological potential of the RM mid-range theory would not be fully exploited if it remained silent about other important related questions. These include:

- Why is achieving RM-based sustainable competitive advantage essentially limited to RM-mature firms only?

- If RM-maturity heavily impacts the ability to achieve sustainable competitive advantage, why have RM-mature firms not seized the whole market?

- What determines the scale and scope of RM-mature firms?

- Are there markets/industries/segments/customer groups that favour RM-mature firms and simultaneously those which do not?

All these questions will be addressed in the following two sections. 


\subsection{The Final Proposal of the RM Maturity Model and Its Practical Interpretation}

From the theoretical point of view, the overall message of this research is that if RBV (extended by the dynamic capabilities concept), SDL and RM are analysed as intertwined theories, employees emerge as the key internal resource, the mother of all intangible resources. Consequently, an ethical IRM capability emerges as a fundamental driver of sustainable competitive advantage, preceding customer (and other external stakeholders') relationship management capability.

On the basis of the final proposal for the RM maturity model, nothing seems to be more important than excellent internal vertical and horizontal communication. Its existence would reveal itself in showing full respect to every person, sincere and sympathetic interest in each other's well-being, being absolutely transparent about individual and group challenges, and demonstrating the willingness to learn and adapt. Whilst this applies to all employees, it is more of a personal challenge for the management. True leadership, in this context, does not end with managers' factual knowledge, but extends to the very core of their humanity, which is a fundamental guiding reference for the team to follow. In turn, this attitude is transferred further into external relationships and consumed as a service (be it a consumer or business partner experience).

RM maturity exhibited in such a way should have a positive impact on both the cost and revenue sides of a business. In the case of management costs, savings may be a result of largely replacing the supervisor-subordinate mode of control by the much more effective mechanism of individual and group self-control (cutting red tape and reducing the corporate "game of deception" in favour of employee empowerment and engagement; Kegan et al. 2014). However, there is more. Sales, marketing, distribution and administration expenses are usually supervariable (they rise faster than sales volume), provided a company expands by traditional means of mass marketing and price promotions (Kaplan and Cooper 1998). If growth is more organic, largely by taking advantage of positive word-of-mouth and customer referrals, the customer acquisition costs are minimized, and the investment in infrastructure (people, processes, physical) keeps up with rising demand. On the revenue side, the use of customer-specific knowledge is likely to create positive sales and after-sales experiences (including co-creation experiences), which enhance the customer propensity to buy more, and more frequently (Reichheld and Teal 2001). 
Hence, the existence of an RM-mature company is determined by its ability to co-create and share value with all its stakeholders, according to their merits and position in the value creating chain. Although a part of this value will have a transactional character, for example the basic utility value of a product or service against the price paid or salary against labour, the real difference is made by the value of relationships, for example manifested in the comfort of having a trusted partner/advisor, or a friendly work ambience. What may sound like a pipe dream is measurable on the bottom line, and this book is not the only one to say this. A notable example is the concept of the Service-Profit Chain (Heskett et al. 2008a). This linkage model shows the relationships between organizational performance and customer and employee satisfaction and loyalty (Sasser et al. 1997). Although there are very few companies who have continuously tried to explore all its linkages, its underlying ideas seem to clearly reflect the practices of leading global service organizations (Payne and Frow 2013). Moreover, even if the original model was publicized as an attractive managerial concept (Heskett et al. 2008b) and not as a theory-based contribution, it corresponds well with the notion of RM maturity. In contrast, the Gallup Institute claims customer and employee engagement potentiate one another and improve overall financial performance by up to $240 \%$ (according to the Gallup Q12 survey instrument, if both metrics score above $50 \%$ in comparison to companies that stay below this level (Robinson 2008)). And in the meta-analysis of 339 independent research studies, Krekel et al. $(2019$, p. 2) found a significant, strong, positive correlation between employees' wellbeing, productivity and customer loyalty, which were ultimately positively correlated with business-unit profitability levels.

Figure 5.1 depicts the final proposal of the RM maturity model, which highlights the key elements of its preliminary version verified in the empirical research. It is evident that almost half of these elements are oriented to managing internal relationships (IRM). Hence, the final proposal of the RM maturity model strongly resembles the strategic dimension of the preliminary version. The main difference between Fig. 3.7 'Strategic dimension in preliminary RM maturity model' and Fig. 5.1 are three key ERM processes labelled as a quick RM-maturity test. All three processes have empirically proven legitimacy directly embedded in research items D03, D05 and D08 linked by the association rules R4 and Rl1-R16 in congruence with items A05 and A06 linked by the association rule Rl. These three processes may function as a compact basic guiding reference for 


\section{Key ERM processes (RM maturity quick test)}
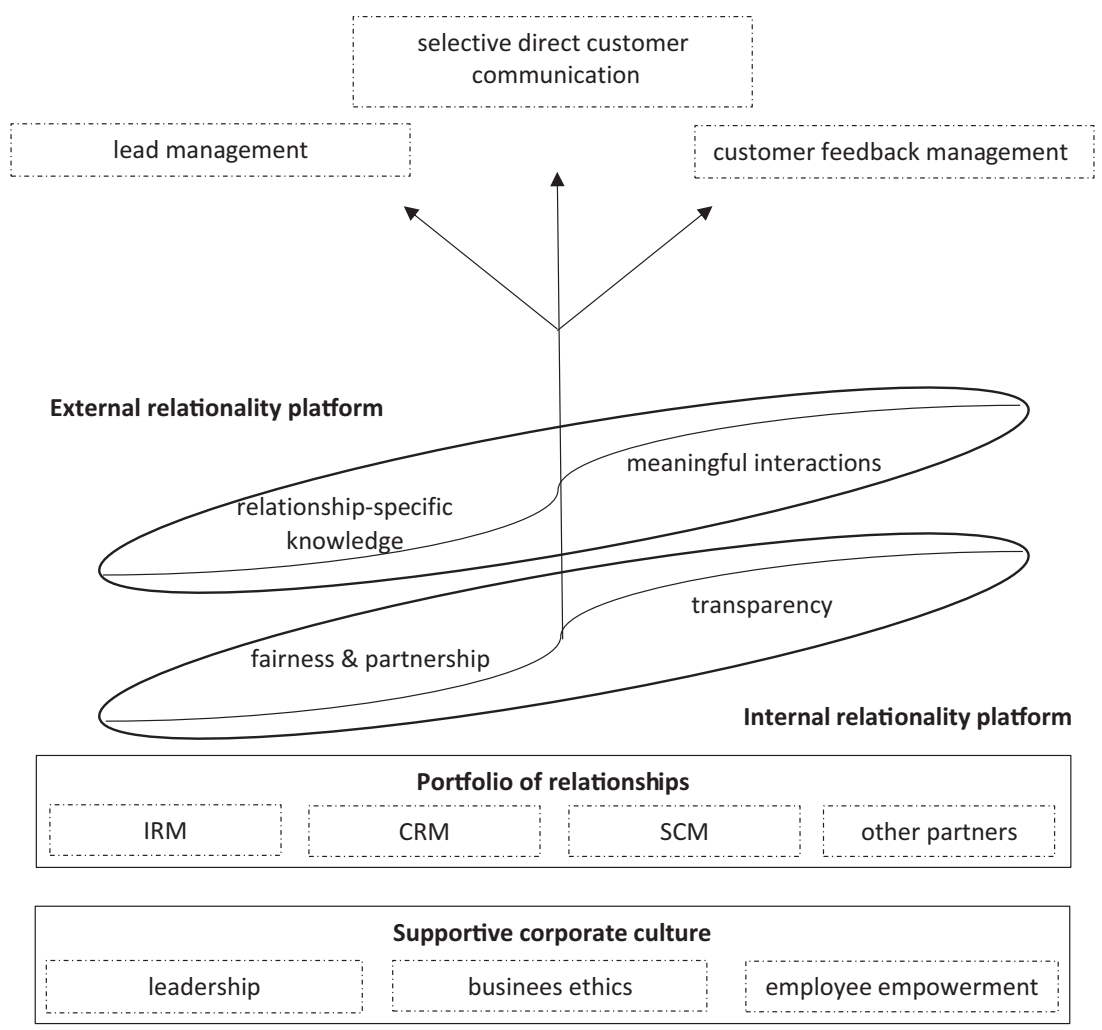

\section{SDL and RM-inspired mission, vision and strategic goals}

Fig. 5.1 Final proposal of the RM maturity model

managers looking to achieve an RM-based sustainable competitive advantage.

In the case of the lead management process (D03), achieving RM maturity means adopting a non-waste lead policy. This translates into systemic utilization of every organically acquired or marketing campaigngenerated customer contact across the whole communication process, starting with the first interaction and closing with the 'deal won' or 'deal lost' status. As a result, the investment in both individual relationship 
development and in marketing campaigns is optimally converted into sales. To ensure the lead management process runs properly, the interested manager should demand transparent reporting on conversion rates at all major stages in the sales funnel. This puts interdepartmental coordination and the quality of internal and external communication to the test (Deszczyński 2016a). For example, the marketing department may launch a campaign, which initially generates much resonance and leads, but the excessive promises used to lure potential customers, which are not supported by the factual attractiveness of the offer, clog the sales funnel with disappointed prospect buyers having no real propensity to buy. The result should be visible in heavy losses in lead conversion in the initial steps, extended waiting time for leads to be processed, and high lead drop-off ratio after passing them on to sales. The same can happen if, for example, the customer contact teams' or sales organization's work is in excess of their capabilities, fulfilling massive bureaucratic tasks or simply being too scarce.

The second area where an interested manager can quickly test the RM maturity of a company is by examining its means of communication (D05). An RM-mature organization should mainly use direct communication channels, because only then is there a possibility for a customer-specific dialogue based on customer-generated knowledge. It is also the prerequisite to co-creating value with customers in an RM sense. However, as indicated by the low scores in the empirical tests of the technological RM dimension, merely having a customer database is not enough. Therefore, a manager should ask whether the company has good answers to the basic yet fundamental questions: "Who are our customers?" "What do they expect from us?" and "When is the best time to tap into their demand?" (Deszczyński 2016b; Lusch and Vargo 2014). In particular, these questions should be addressed with a view to identifying the relatively small group of the most valuable customer relationships which, according to the Pareto principle, largely decide a company's prosperous development (Buttle and Maklan 2019). The capacity to maintain selective, adaptable, largely autonomous interactions with these key customers should be the hallmark of an RM-mature company. This puts the motivation and engagement of the front-line personnel to the test. Much of the content of these highly satisfying interactions cannot be centrally set or controlled. Truly meaningful one-to-one interactions are only possible when both the customer and the employee are empowered to flexibly integrate the resources the company provides (Lusch et al. 2007). However, this means that the 
company partially loses control over the way its resources are allocated, which poses some problems to organizations not having developed a partnership with their staff (Mayer et al. 2010). First, the employees may not be ready to take on such a responsibility (Ahearne et al. 2005; Barner 1994). Second, they may use such an opportunity to commit fraud or for indirect personal benefit at the expense of a company (e.g., buying customer silence to spare excessive work or to cover up errors committed; Comer 1998; Hooks et al. 1994). If there is a high risk that one or both of these problems may occur, relational communication and relational selling will not be possible, and thus the company will not be capable of achieving sustainable RM-related competitive advantage.

Finally, the integration of customer feedback into a firm's continuous improvement efforts (D08) has to be examined. For an RM-mature company, the willingness of customers to participate in a dialogue is a chance for further developing the relationship. There are, of course, varied reasons customers may wish to interact with the company. In fact, both lead management and selective direct customer communication are also processes built on interaction: the first mainly of a transactional type, the second of transactional and non-transactional types. However, an organization can only actively shape its future by seeing beyond the current customer loyalty cycle. Therefore, an interested manager should make sure that, as with leads, no customer request or complaint passes without analysis and response. The annual aggregated complaint statistics may expose some trends, for example in the general quality of customer encounters, but only short loop analysis by the responsible team gives the company a chance not only to restore the individual customer's trust, but to mitigate the risk of committing the same mistakes again soon (Wirtz and Tomlin 2000). A strong indicator for making the management of customer feedback a priority among other business goals is its incorporation in the employee assessment system (Pollack and Pollack 1996). If a company recognizes and rewards only immediate sales increase or cost reduction, this sends a clear 'it's all about the money' message to its employees. Such a tactic reduces their perspectives to the forthcoming bonus cycle and is an example of paraded RM (Lusch and Vargo 2014). Similarly, care for the quality of customer encounters may also take the paraded form if employees are only penalized for reported problems instead of treating this as an opportunity to learn from mistakes (Wirtz et al. 2010).

What might an interested manager do if facing such problems? Of course, they may try to tackle them at the operational level, but what this 
research suggests is that such problems are unlikely to occur without any fundamental reasons caused by lame IRM. A company that deprives salespeople of the willingness to cultivate long-term profitable relations or that is pretending to be satisfied by an tentative and undifferentiated 'omnivorous' sales approach is also most likely having problems with employee turnover, morale and widespread mediocrity caused by toxic corporate culture, devoid of inspiring goals and leadership. Probably the most concise answer to the question of what companies should do to achieve and sustain RM-related competitive advantage is the 'Employees first, customers second' transformation started by Indian IT-services giant HCL, which was publicized by the company's former CEO V. Nayar in his similarly titled book (2010). By acknowledging that it is the employee/customer interface where the most value is created, companies like HCL find motivation to turn conventional management upside down and become a company of 'ideapreneurs'-self-run, self-governing and highly profitable (HCL 2020).

Why corporate success may have IRM-based roots is also presented in two of the illustrative examples of RM practice provided in Sect. 5.3. The first (Illustration 1) shows the volatility of corporate culture in the example of 'Medium-sized home décor online retailer', where a single person undermined the very core of the firm's identity in the shortest time. The second (Illustration 2) presents the redefinition of the roles of managers and employees in a 'Large manufacturing company operating in the FMCG market'.

\subsection{Relational Niche}

Defining the RM recipe for achieving sustainable competitive advantage begs the question: Why is it a relatively exclusive strategy? After all, even bringing together the 'extremely strong competitive advantage' group of companies with the 'strong competitive advantage' group (which includes companies having reported some of the long-term competitive advantage indicators while being able to report only one out of 16 rules characterizing RM maturity based on the 9/10-score level) only accounts for roughly $19 \%$ of the whole examined company population. Probably the best explanation of this phenomenon can be deduced from the nature of loyalty. Although the notion of loyalty has been addressed several times in this book, at this juncture a short recap is needed. 
The state of being loyal to anybody or anything has to have strong reasons, because patronizing one object of some kind automatically implies refraining from others, thus narrowing one's choice (Varelius 2009). In many product/service categories, the differences in utility (based on similar technologies) and in brand perception (following the homogeneity in marketing messages and loyalty programmes) are very small (Uncles et al. 2003). As all alternatives are likely to be satisfactory, there is little opportunity for anything more than superficial habitual loyalty (Wood and Neal 2009). This is because the perception of the purchase as a transaction that fully accommodates the exchange (based on the pure market-pricing mechanism; Fiske 1992) leaves no room for the important loyalty-driving equality-matching mechanism of reciprocal gratitude (Fiske 1992; Henderson et al. 2011;). Its occurrence is more likely when the customer has developed loyalty ties to (an) individual employee(s) (Palmatier et al. 2007). They, in turn, are related to a history of successful interactions incorporating value co-creation and partnership that appears to be benevolently motivated and offered just as the customer needs assistance (Palmatier et al. 2009). However, a randomized quality of encounters cannot evoke customer attitudinal loyalty, just as a friend who is only occasionally willing to help is not a real friend. Offering a 'merely' good level of service is only enough to become an acquaintance, alongside many others. Thus, the external manifestation of RM maturity that can be assessed by customers is either continuous, highly personalized, 'intimate' customer encounters or top-notch quality of individualized solutions based on a deep understanding of customers' needs and purchase motivations, or, preferably, both (Payne and Frow 2013).

The issue of individual relationships between customers and employees is discussed in two further RM illustrations. Illustration 3 discusses the impact of informal relations on business relations and its changing characteristics over the last 30 years upon the experiences of Pamapol, a large ready meals manufacturing company. Illustration 4 shows the role of personal relationships between high-ranked managers in the example of 'Medium production company representing chemical industry'.

The sketched dichotomy between delighting customers to develop relationships that last and 'only' fulfilling the expected standards and luring random customers to conclude a single transaction is clearly reflected in the Net Promoter Score (NPS) concept and methodology (Reichheld 2003). Labelled as a 'highly aggregated RM capability indicator' in the previous chapter, NPS precisely measures the ability of a company to 
deliver the high-end performance reflected in total customer satisfaction and in the willingness to repurchase and make referrals to other customers. The design of NPS with only $9 / 10$ scores linked to customer loyalty reproduced in the RM maturity research methodology indicates that, unlike a typical maturity model, there is nothing like an RM maturation path (De Bruin et al. 2005), at least in the sense of establishing a linear relationship between subsequent levels of quality in customer encounter, customer loyalty and the company's bottom line. Instead, the sharply curvilinear correlation (Reichheld and Markey 2011) supports the totality of the RM maturity model exposed in the empirical hypothesis Hle. However, this does not provide an answer to the next question: How is it possible that RM-mature firms did not outcompete the transactionoriented ones and what limits their scale and scope? For example, in Forrester's 'Net Promoter Benchmarks, 2019 (US)', the overall NPS scores ranged from +59 to $-47^{1}$ (Schmidt-Subramanian 2019); this means that the companies that achieved an almost $60 \%$ net predictive loyalty rate coexisted with those whose customer base predominately included detractors. Moreover, $25 \%$ of the interviewed companies in the research presented in this book reported growing sales, expansion to new markets or sometimes even scoring above-average profits without achieving RM maturity.

The coexistence of companies applying different business models and strategies, having diverse corporate cultures and structures, servicing different industries and market segments, and achieving varied business results has been the reality noted by many researchers (Romanowska 2014). One of the most fruitful research traditions in this respect is configuration theory, which posits that, for companies to be successful, they have to match their organizational characteristics with the adopted business strategy (Slater et al. 2011). Prominent representatives of this tradition, O. Walker and R. Ruekert, in their award-winning article (1987) defined companies in terms of two dimensions:

- the intended major method of competing (cost leadership and differentiation), which they adopted from M. Porter's strategy framework (1979);

- the desired rate of new product-market change (aggressive position in a broadly defined market-Prospectors, and conservative position in a narrower market segment-Low-cost or Differentiated Defenders), which they adopted from R. Miles et al.'s strategy-structure-process typology (1978). 
Their findings based on theoretical and empirical evidence were that the strategic fit between the adopted generic marketing strategy and its internal characteristics (structures, policies, programmes, procedures) heavily impacts business performance regardless of how the adopted strategy fits the changing external environment (1987). Interestingly, the detailed characteristic of Differentiated Defenders strongly resembles the RM-mature company (Olson et al. 2018; Slater and Olson 2001):

- relatively high quality of well positioned products and services;

- relatively high prices and sales force expenditures;

- relatively greater forward integration;

- customer relationships as most valuable assets;

- customer service and product/service innovation as core competences.

What is also particularly noteworthy is that in O. Walker and R. Ruekert's empirical research and the work of researchers that followed them, among three identified types of companies, the Differentiated Defenders scored best in terms of return on investment (ROI), while being less successful with market share and new products; the Prospectors were quite the opposite; whereas the Low-cost Defenders were fairly successful when it came to ROI, but very poor in new product development (1987, p. 20).

Also, diversification theory explains the coexistence of differently performing firms. Its foundational premise links expansion with excess capacity of productive factors and stipulates that the wider a company diversifies, the lower will be its average margins (Teece 1982). Further on, diversification theory links the average margins with the specificity of these factors. The more specific the factors (in RBV terminology, the more these factors resemble VRIO resources and dynamic capabilities), the higher average margins can be generated in new markets, provided the new market entry opportunities are located 'nearby' - that is, the new application of company resources and capabilities does not require them to be modified extensively (Chatterjee and Wernerfelt 1991). Therefore, companies with specific, idiosyncratic resources and capabilities will generate high average margins when diversifying narrowly or not diversifying at all, while companies with less specific resources and capabilities will generate medium average margins when diversifying narrowly and low average margins when diversifying widely to 'distant' new market opportunities (Montgomery and Wernerfelt 1988). 
By combining what configuration theory and diversification theory have to say about resource specificity, market focus, and business performance and by relating it to RM-mature firms, one can assume that these entities are likely to adopt a niche strategy. Traditionally, niche marketing strategies were associated with small innovative firms concentrating on product innovation matching new technology with unmet customer needs (Pavitt 1990). However, the definition of a niche market does not explicitly imply that its borderlines are of a technological nature (Stankiewicz 2000 ). It is enough that a niche is sufficient in size and shows the potential for profitable growth based on the goodwill of customers who expect special treatment and who have been, up to now, ignored by companies supplying the broad volume market (Dalgic 1998).

How about a relational niche? A subdivision of a market with only one company focused on a niche of customers, which has built an ecosystem of mature relationships stabilizing and growing its business through an RBVstyle mechanism of isolation that prevents imitation (Galvão et al. 2018; Lepak et al. 2007)? Such a company could largely coexist undisturbed with neighbouring major players fighting for market dominance in a pursuit of a monopolistic rent (Teece 1984), while building its own sustained competitive advantage on a relationship rent (Dyer and Singh 1998). Consequently, instead of wasting resources on analysing and counteracting rivals' activities (strategizing), it could concentrate on co-creating superior value (economizing; Williamson 1991) and generating excess surpluses, which could be shared with its partners.

It seems that virtually every industry offers a room for a relational niche even in, to date anonymous, B2C markets. Let's take the breakfast cereals segment as an example. End-customers have traditionally purchased this product via extensive FMCG (fast-moving consumer goods) retailing distribution networks. Yet, some of them are now ordering breakfast cereals online from specialized providers, who offer a number of product variations which no shop shelf would ever accommodate plus individualized nutrition advice, recipes, and customer care powered by online behaviour tracking. In contrast, let's examine the roots of success of a small grocery shop. For a number of clients, the proven freshness of food and its traceable origins, the convenience of individualized orders, and the comfort of personal chat with the shop assistant could be the arguments prevailing over the competitive price and the wide availability of merchandise offered by retailing giants. Both entities may successfully operate in niches separated from the surrounding volume markets, through major distinguishing characteristic of high quality-oriented customers. 
The two examples provided may leave the impression that relational niches are, by definition, very modest in size. However, a company servicing a relational niche does not have to remain nominally small provided the demand for personalized customer encounter and/or highly individualized quality offerings is sufficient high, or its relationships can be extended or used in other market segments. The example of KonimpexInvest (Illustration 5), a medium-sized real estate development company, demonstrates that a company can even place the bulk of its operations in the volume single transaction market, while proactively catering to the needs of these customers, whose special preferences create room for separating a profitable relational niche.

Figures 5.2 and 5.3 will be helpful in further discussing the coexistence of RM-mature and RM-immature firms. They depict two market situations. The initial one is a model of a market with two transaction-oriented rival companies $\mathrm{Tl}$ and $\mathrm{T} 2 .^{2}$ These companies devote a great deal of resource to acquiring new customers; however, as they conclude a transaction, their interest in customers sharply disappears. In turn, most of their

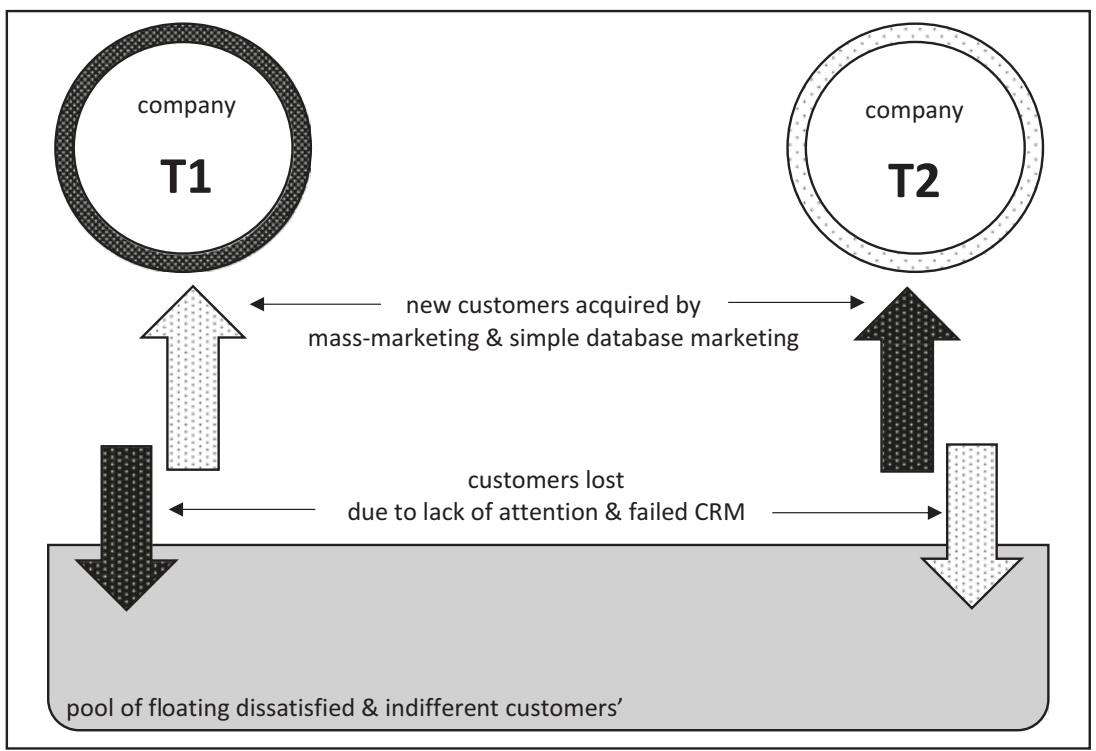

Fig. 5.2 Model of transactional rivalry. Note: The picture has an indicative character and does not show oligopoly. The actual number of companies does not matter as long as customers have a choice of comparable alternatives 


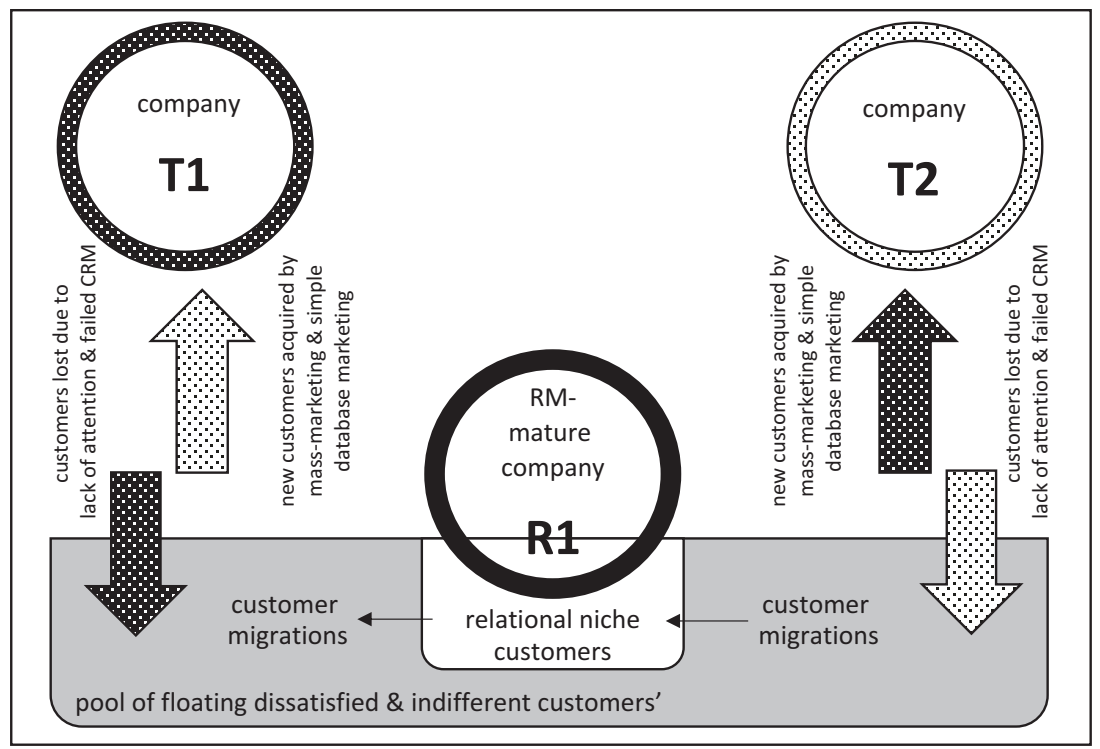

Fig. 5.3 The coexistence of RM-mature and transaction-oriented companies. Note: The picture has an indicative character. There could me more RM-mature companies in the market, which would isolate their relational niches. There could be cross-sections of these niches; however, the modus operandi of RM-mature companies would remain the same

newly acquired customers are dissatisfied or find no strong reasons to stay loyal and migrate to the 'floating customers' pool.

Therefore, to sustain their business, companies T1 and T2 have to concentrate even more on acquiring new customers whom they, by definition, do not know well. In consequence they often communicate by using very simple and unspecific arguments (e.g. price promotions) via mass marketing channels trying to appeal to an 'average customer'. By continuing this modus operandi, they sustain a vicious cycle of mutually 'exchanging' dissatisfied and indifferent customers at a cost of high marketing spending aimed in counteracting their rivals' offers (strategizing) in a relatively homogenous market (Peteraf 1993). This is a familiar picture perfectly depicted in M. Porter's Five Forces Model (1979). The notion of RM-maturity implies that this model of competition will not substantially change even if rival companies were to temporarily gain a partial competitive advantage based on low-scaled RM-resources (e.g. a single highly-engaged 
sales team or an individual employee). One can expect that within a short time, any major customer-centric initiatives in such companies are likely to be dragged down by the dominance of their volume-oriented focus, which implies the need to compensate excessive marketing costs by cutting expenses on customer care. In the end neither these companies nor their customers (and presumably most of their employees) create optimal value.

Alternatively, it is also possible that due to some market or macroeconomic policy failure these companies will refrain from competing and will instead fix prices, limit or control production, markets, technical development, or investment. Oddly enough, such collusions are also the outcomes of corrupted RM aimed at satisfying the interests of corporate elites only. Such RM-based collusive practices are illustrated by the example of the bidding process for water rescue services for Termy Maltańskie, the biggest waterpark in Poland (Illustration 6).

Figure 5.3 shows the same market occupied by transaction-oriented rivals $\mathrm{T} 1$ and $\mathrm{T} 2$. In addition, a third player, the RM-mature company (Rl), enters the market. However, although Rl offers superior quality of customer encounter, it does not seize the whole market. Instead, it isolates a part of the market populated by the most demanding quality-oriented customers, who can afford to pay a premium on an offer that optimally caters to their needs (relational niche-customers). To differentiate by effective offer personalization, company $\mathrm{Rl}$ is virtually immersed in the niche its serves by receiving even faint signals sent by its customer base. Occasionally some customers leave and some enter its relational niche, but it remains stable as long as the company cultivates its relationships and no major external shock occurs (e.g. radical technological change which the company was not participating in). Company $\mathrm{Rl}$ does not expand more than its relationship resources and the demand of relational nichecustomers allow. Thus, companies T1 and T2 may continue their competing strategies, barely noticing that the market they operate in is now somewhat smaller. They may also try to attack the position of company $\mathrm{Rl}$, but as they fundamentally lack the RM competitive factors these attacks can only appeal to the peripherals of the relational niche, where relatively more price-sensitive customers reside.

The idea of the relational niche equally explains the coexistence of transaction-oriented (RM-immature) and RM-mature companies as well as the somewhat limited scale and scope of the latter. As the relational rent resembles a Ricardian type of rent, it is generated at maximum output. Thus, the growth of an RM mature company is limited by the uniqueness and scarce supply of its relationship capital (Peteraf 1993). The rapid 
elastic growth is, therefore, impossible unless the company decides to finance expansion at the expense of relationship capital. This may yield additional volume and short-term financial benefits; however, as the isolating mechanisms of the firm's niche are the relationships it maintains, these barriers will disappear once those relationships weaken. In this context, the most likely threat to the comfortable position of an RM-mature company is the company itself. After all, it does not take long to destroy what was previously an unconquered fortress from the inside, for example, by hiring some new managers who pull their weight, instead of motivating their teams (this risk is showed in Illustration 1) or by doubling the number of customers served per employee. This is probably also one of the reasons for the ambiguity of links between RM and company performance highlighted in the introduction, in the theory-methodic hypothesis $\mathrm{Hltm}$, and generally throughout this book. When a company has abandoned its relational niche some time ago (e.g. for the sake of realizing ambitious volume expansion plans) and it faces unstable or price sensitive demand, but still classifies itself as RM-oriented, this can be misinterpreted as evidence for RM-strategy failure.

What still remains unaddressed is the size of the relational niche. Admittedly, there will be markets where the process of cultivating a relational niche will be easier and others where the potential niche will be 'by nature' very small. This seems to be a boundary issue between the RM upper mid-range theory and the RM mid-range theories of particular market types (compare Chap. 2 Fig. 2.4). The latter may address more specific, e.g., industry-based factors affecting the characteristics of the relational niche, while the RM upper mid-range theory may discuss the universal ones.

An analysis of the universal external factors having an impact on the size of a relational niche should begin by examining whether a company may have direct access to the customers. Based on social network research, such as M. Granovetter's work on the "strength of weak ties" (1977), one can assume that the better this is, the more likely a significant relational niche could be developed. More precisely, in line with the media multiplexity theory (Haythornthwaite 2000), the level of interdependence between the actors in a relationship is positively associated with the number of media used in that relationship (Haythornthwaite 2005; Ledbetter 2010). If a given market is anonymous, companies can only observe general trends in demand and may eventually try to establish a brand preference through diverse marketing activities. This situation applies to the 
aforementioned FMCG market as well as to all industries where the suppliers (mainly manufacturers) sell their offers through independent intermediaries (Payne and Frow 2013). Even if they may occasionally connect to their end-clients by organizing prize competitions or surveys, these companies were traditionally not in a position to maintain a dialogical communication. However, some of them may break the impotence of mass communication by virtualizing their operations, just as indicated in the example of specialized breakfast cereals suppliers. Still, the additional logistics costs and the inability to purchase all the complementary products (e.g. milk, to stay with the cereals example) or the unavailability of the broad merchandise that is conveniently offered together (e.g. food in the supermarket, which is situated in the shopping mall that accommodates other types of shops) should normally significantly reduce the potential size of the relational niche such companies can tap into. In other words, there will be fewer customers potentially interested in developing relationships with a specialized supplier/provider, the more inconveniences such relationships demand.

Four issues are worth commenting on at this point. The first is the role of online shopping platforms such as Allegro and Amazon. Their intermediation removes the inconvenience of separate shopping for different types of products. Some product categories may be even better represented, compared to traditional distribution channels (while others, such as fresh food, are worse). However, these platforms do not provide tools for developing end-customers' loyalty towards their merchants, as this would undermine their position as intermediaries. Therefore, they help in achieving volume goals rather than in cultivating relationships (Dolata 2017).

The second issue is the role of social media technologies. Although useful in creating online brand communities, these tools do not have (at least currently) the potential to effectively integrate and manage all points of customer contact, including transactional contacts. Nonetheless, in the case of fully virtual communication modes, the integration of social media with other online tools, such as e-commerce platforms and CRM systems, may open the gate wider to connecting to niche customers and nurturing relationships with them (Chatterjee et al. 2019).

The third issue is that every company can try to develop relationships with its direct business customers, who may well have very specific needs that can be best met by a specialized partner. The inexistence of fundamental barriers in locating and communicating to $\mathrm{B} 2 \mathrm{~B}$ customers makes the relational niche an even more likely phenomenon than in the $\mathrm{B} 2 \mathrm{C}$ 
market setting, where the large number of customers necessitates, for example, the investment in CRM systems implementation to effectively manage all the interactions (Buttle and Maklan 2019).

Finally, the fourth issue is that even relatively easy access to customers does not automatically imply the existence of a relational niche. Take telecommunications and cable television providers. As these services are predominately offered on a contractual basis, their providers are in a superior situation compared to, for example, durable goods manufacturers. Still, this industry has traditionally suffered from one of the highest churn rates, even if the average loyalty cycles sanctioned by these contracts are relatively long (Ahn et al. 2006; Kotler and Keller 2009). However, as the main focus of these firms is placed on attracting new customers, the relatively frequent direct contacts they maintain with their customers (based on monthly billing) do not necessarily create customer satisfaction. The most evident proof for the illusion of fake contractual loyalty was the mass defection movement as soon as governments across the globe introduced wireless number portability laws (Eshghi et al. 2007).

Two companies from contractual industries showcased in the RM-Illustrations are currently coping with the challenge of maintaining a true focus on their relationships. Sugar-refining group (Illustration 7) discovered how undeveloped its business relationships were as soon as the sugar market was deregulated in the European Union. By contrast, Aquanet (Illustration 8), a water and sewage processing municipalityowned company, decided to improve its relationships with individual and corporate clients by starting first to improve its relationship with its employees.

Another universal factor that should have an influence on the potential size of an RM-niche is the relative importance of the given offer category for the customer's overall value creation chain. It should be significant and enduring enough so that interested firms could develop a performance gap reflected in the relationally-affected key buying attributes of their offer that make true difference to their targeted customers (Bharadwaj et al. 1993). In the case of B2C markets, it will be the extent to which the offer impacts the lives of individuals based on the personal psychographic and behavioural context (Zhang et al. 2017). In the case of B2B markets, it will be the share that the offering may have in the corporate value adding process (Hakanen and Jaakkola 2012). Although price may be regarded as only a simplified measure of that influence, one can assume that the higher the monetary value of single transactions or alternatively the cumulated 
value of frequent transactions that are typically concluded in a given market segment, the more important the offer category and the more likely a relational niche can be developed. On the one hand, a nominally high price implies that customer offer evaluation is likely to be complicated and involve a time-consuming learning process necessary to acquire enough knowledge and skills to effectively assess the offer and integrate resources to facilitate value-creation (Hibbert et al. 2012). For example, while consumers tend to choose casual garments on impulse, tailored clothing necessitates some search for the craftsman, advice taking, and active cooperation as measurements is taken and the suit is sewn. Similarly, the procurement department can autonomously acquire standard machining blades replacement, but if a new manufacturing line is being designed it will be the whole team of specialists that work together with the vendor to search for new ways of reducing time and waste, and increasing the reliability of the new solution. In both advanced situations the intensity of interactions and the individualized value they produce open the way for capable companies to create their own relational niches. Simultaneously, high price creates room for high premiums, which can be partly reinvested in the relationship (e.g. customized technical solutions or process design, preferential treatment policies, and individualized communication). Such special commitments further stabilize the relationships and make creating and sustaining the relational niche even more probable (Pervan et al. 2009).

An additional factor that can indicate the relatively high importance of the given product category, especially in $\mathrm{B} 2 \mathrm{C}$ markets, is its potential to emotionalize communication. If consumers become somehow bonded to the brand or can admit that they feel something akin to love or friendship for the brand, they substantially increase usage and purchase of the brand (whether product or service; Morrison and Crane 2007; Rossiter and Bellman 2012). Obviously, not every brand in a category will manage to advance beyond rational perception. For example, some cars are bought mainly for mobility reasons, while others are a symbol of success and prestige as well. Nonetheless, thanks to a relatively strong person-product relationship, car manufacturers have a generally much better starting position for emotional communication than, for example, photo camera producers (Mugge et al. 2005). They, in turn, may generally count on more customer emotional attachment than manufacturers of cosmetics, and so on. Therefore, for consumer markets, where emotional attachment for products may exist for a significant group of customers, a relational niche may 
well also exist, provided these customers may be effectively directly contacted by the company.

Through the discussion so far on the universal external factors that impact the existence of a relational niche, the issue of services has been left unaddressed, except to place it in the context of the other factors. Owing to the classification of RM-mature companies as being basically similar to Differentiated Defenders and the extensive explanation of the overlaps between RM and SDL provided in Chap. 3, one can stipulate that the likeliness and the size of a relational niche will be also dependent upon the degree of 'servicization' that can be applied in the given market segment.

There are four basic categories of services, which are directed at (Lovelock 1983):

- peoples' bodies;

- physical possessions;

- peoples' minds (mental stimulus processing);

- intangible assets (information processing).

While the first two categories are tangible actions whose effects are visibly projected in, for example, a new haircut or shipping a parcel, the other two are intangible actions. Apart from being standalone service categories (e.g. education and banking), they may be an ingredient of every offer (Wirtz and Lovelock 2016). For example, 17 out of 22 questions employed in SERVQUAL - one of the widest applied instruments for evaluating service quality - have an intangible and usually employee-related focus (e.g. "Excellent [companies] will give customers individual attention", "Employees of excellent [companies] will always be willing to help customers"; Parasurman et al. 1988; 1991).

While tangible characteristics of the offer can be relatively easily researched and compared before purchase (e.g. price, location, technical equipment, ingredients), the intangible ones constitute the most variable and flexible part of the offer that is rich in experiences and credence-based (Parasuraman et al. 1985). Therefore, they usually dominate value creation and its overall perception because they incorporate such attributes, which are difficult to evaluate even after consumption. Their evaluation process necessitates adopting some kind of a proxy, which is commonly a matter of having belief in the benevolence and skills of the offer provider (Lovelock et al. 2014; Schumann et al. 2010). For example, the hairdresser has to master their craft which, in fact, most hairdressers do. 
However, whether the client feels comfortable, is amused, and appreciates the work done largely depends on the small-talk concerning client-relevant topics and the personal aura given off by the hairdresser. This suggests that value perception is phenomenologically determined by the temporal, spatial, and social context (Vargo et al. 2020). This, in turn, implies the need for ongoing micro-adaptations, which can be best applied at the employeecustomer level. Figure 5.4 lists all the discussed external factors having an impact on the likelihood of the existence of a relational niche.

At this juncture, however, an important remark has to be added. The intangibility of service elements should not be artificially applied just for their own sake. For example, banking (especially internet banking) is probably one of the most intangible types of service (Shostack 1982), and yet financial institutions are believed to suffer from exceptionally high annual churn rates ranging from $20 \%$ to $27 \%$ (du Toit and Burns 2014; Kotler and Keller 2009). However, if the two intangible service categories

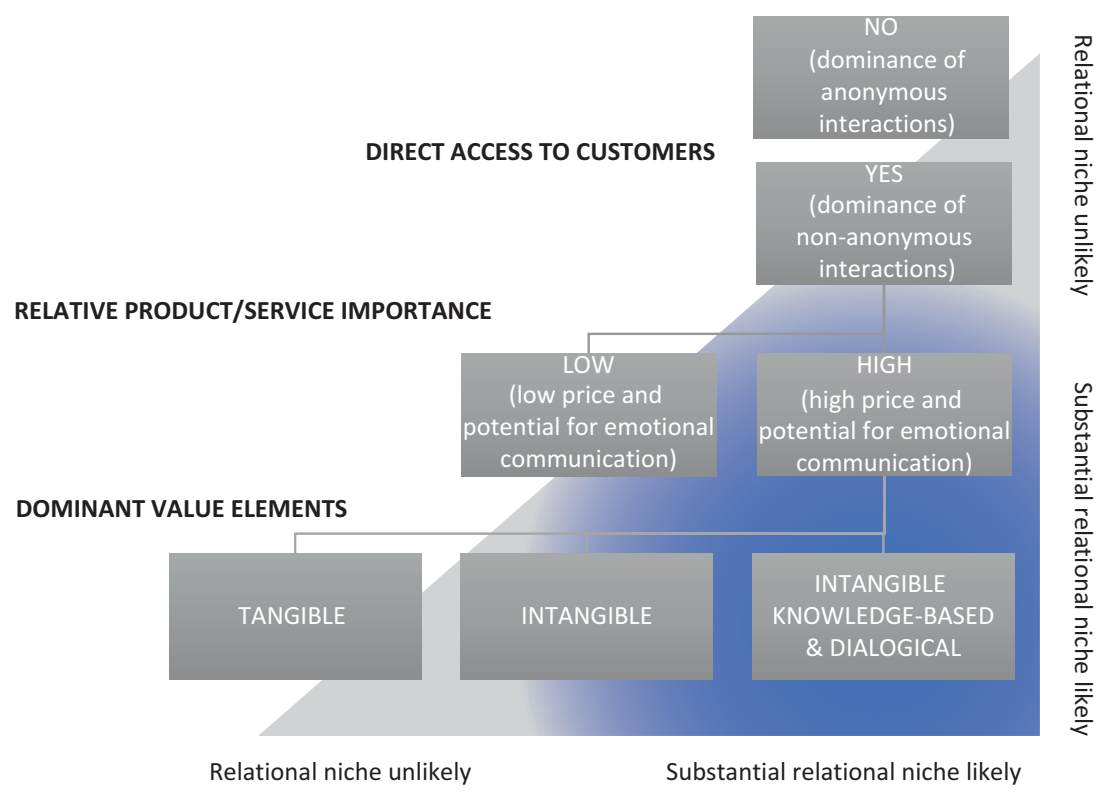

Fig. 5.4 Factors influencing the size of relational niche. Note: The more intense gradient in the triangle, the more likely a substantial relational niche can be built 
can be balanced and effectively designed in the overall offer, the chance for cultivating a relational niche by capable companies should be higher. This is because the intangible elements of service are simultaneously the essence of CRM (Grönroos 2017), which in its highest form is both knowledgebased and dialogical (Payne and Frow 2013), and ultimately co-creative (FitzPatrick et al. 2015). Hence, although the emergence of a relational niche is influenced by the discussed universal external market factors, its development is, in the end, a function of a company's ability to effectively differentiate on the basis of customer-perceived individualization. In other words, it is primarily the maturity of company's relationship management activities and approaches that creates a relational niche.

Further discussion on the characteristics of a relational niche leaves the area reserved for the RM upper mid-range theory and enters the realms of the RM mid-range theories of particular market type. These should, inter alia, address the following issues:

- What are the detailed premises which favour the existence of relational niches and RM-mature firms in different markets and in different industries, segments, and customer groups?

- How can new technologies or business practices help in crossing the borders into markets where RM-mature firms were traditionally not represented?

- Can a company partially adopt an RM business model in a given market or segment, while remaining transaction-oriented in others?

- To what extent does the phenomenon of RM-maturity influence the company business network?

- Do RM-mature networks exist, and do they successfully compete in markets?

- What are the barriers for successful RM business model implementations in a given organization type with regard to their size, structure, commercial goals, business partners, etc.?

To address these issues, a series of programmatic industry-specific research is needed. In this book, a small contribution to achieving these broadly-set research goals are the following illustrations which complement this chapter. 


\subsection{Illustrative Examples of RM Practice}

In course of the RM-maturity research project the author of this book visited several firms in search for stories of RM 'in motion', which could deliver first-hand observations illustrating some of RM-facets and challenges companies face in implementing RM business model. Although they do not have a theory-building or theory-confirmative role, they may help the reader to comprehend and interpret the theoretical material and the qualitative empirical evidence provided in Chaps. 2, 3, 4, and 5. This book contains eight such RM-Illustrations, which were briefly announced in this chapter. They were chosen upon the criteria of their horizontal compatibility and the quality of presented examples dealing with a particular RM-area.

The material was collected in course of direct face-to-face and/or telephony interviews with up to four employees currently employed by the company. Their positions and work experience as well as other details concerning the companies are provided within every illustration. Every interview lasted between 60 and 90 minutes. The interview was semi-structured upon the RM-maturity questionnaire, which was sent to the interviewees in advance. Nonetheless, by evoking subsequent elements of the preliminary RM maturity model reflected in the questionnaire the author aimed in involving the interlocutors in a deeper analysis of one or two most important features of their corporate reality with a clear RM context. As mentioned in Chap. 4, the interviews had also helped to test the questionnaire before the field research started.

The filled-in questionnaires and the author notes were used to compose the texts that were all sent back for review and (where needed) to be supplemented. In several cases this involved consultations with other than the originally interviewed persons. For internal firm policy reasons, some of the illustrations had to be anonymized what, however, made it possible to leave the material classified as sensitive intact. Although RM-Illustrations are generally separate contributions, some of them include comments, which repeatedly link the observed phenomena. 
Illustration 1. International medium-sized home décor online retailer (Home décor retailer)*

\section{Interviewees}

1. Interim manager (sales, marketing, finance), employment history: 4 years.

2. Finance manager, employment history: more than 5 years.

3. Production manager, employment history: more than 5 years.

4. Marketing department employee, employment history: 3 years.

5. Marketing department employee, employment history: more than 5 years.

6. Sales department employee, employment history: more than 5 years.

\section{General Corporate Profile}

The company was founded in 2003 in Cracow by a Dutchman, who spotted the chance to take part in the dynamic growth of the Polish e-commerce market. He chose a niche segment (at that time) of high-quality individualized home décor products.

Currently Home décor retailer is present in 17 international markets, including the US-market, where it uses Amazon and eBay online platforms. Despite the fact that the company maintains a zero stock policy, the full order-production-delivery cycle for the American market takes only five working days. Approximately $70 \%$ of the 50,000 monthly processed orders are delivered via the intermediation of big e-commerce portals. In addition, Home décor retailer cooperates with a few hundred small e-shops. In both distribution channels the dropshipping model is applied: the order is processed via the webpage of an e-shop or e-platform, and production and delivery is handled directly by Home décor retailer. The third distribution channel are own e-commerce shops, which use own company brand or one of the brands from the company's portfolio.

The company employs more than 250 people, mainly in production, sales, marketing, customer care, and IT. These are simultaneously the business areas which, apart from product quality and reliable logistic processes, play a crucial role in shaping the company's success. The company is highly dependent on customer satisfaction indexes, which constitute its daily performance review. They directly impact the choices of subsequent buyers and influence or sometimes even condition the possibility to sell via reputable e-commerce portals. The overview of the company's characteristics is given in Table 5.1. 
Table 5.1 Overview: Home décor retailer

\begin{tabular}{|c|c|}
\hline $\begin{array}{l}\text { Number of direct } \\
\text { customers }\end{array}$ & Thousands of customers \\
\hline Number of employees & Between 250 and 999 \\
\hline Main market served & $\mathrm{B} 2 \mathrm{C} / \mathrm{B} 2 \mathrm{~B}$ \\
\hline Main business focus & Production with commerce structures and customer service \\
\hline $\begin{array}{l}\text { Polish classification } \\
\text { of business activities }\end{array}$ & Production/commerce \\
\hline $\begin{array}{l}\text { Dominant } \\
\text { management style }\end{array}$ & $\begin{array}{l}\text { Centralization of decisions in the hands of top management, } \\
\text { multiple layers of management, work standardization and } \\
\text { formalization, big organizational units }\end{array}$ \\
\hline Main perceived & The owner/president of the company \\
\hline success factors & Highly qualified and engaged team \\
\hline Competitive & Steady expansion in terms of sales or market share \\
\hline advantage indicators & Steadily ahead of competitors in terms of profits \\
\hline (in the last two & Entered a new market \\
\hline years) & Steady increase of employment \\
\hline & Steadily ahead of competitors in terms of customer satisfaction \\
\hline
\end{tabular}

* Descriptive company name-the company representatives agreed to share information only under the condition its name will not be revealed. Some of the company's characteristics, which could lead to its identification, were changed. They, however, do not influence the core substance of this illustration.

\section{Main Focus of Illustration \\ Corporate Culture}

\section{Description}

Although revenues are always of crucial importance, for the top management of Home décor retailer, a good working ambience is even more important. The company's management defines this as smooth communication, the enthusiasm to learn from each other, and the acceptance that people sometimes make mistakes. In this company every manager knows much about their employees and is interested in their talents, problems, and life in general. The company promotes the 'attitude of wealth' among its managers (inspired by Charles Richards' book-Psychology of Wealth). According to this approach, the value of a manager is reflected not only in their personal achievements but also in what their employees achieve. It increases the willingness to share knowledge and experience from fields other than the company's own business. An example can be lectures organized in the company, which touch topics other than e-commerce with the aim of stimulating 'out-of-the-box' thinking, such as "How to make a 
company bankrupt in half a year" or "Unknown masters: how middlesized German family businesses became leaders in their niche segments". Mutual openness and the feeling of belonging to a valued team of people make employees who made a mistake feel personally affected and disappointed. Therefore, instead of additionally penalizing them, the company concentrates on drawing conclusions which will be helpful to avoid committing the same mistake again. Penalties are perceived as a tool that does not motivate to better performance, but leads to hiding mistakes.

The great commitment of the company's leadership to a positive work ambience is reflected in some recent incidents. Home décor retailer employed an experienced British e-commerce consultant. This person was looking down on others and acted as if he had a monopoly on good ideas. Having extensive plenipotencies, the consultant wanted to introduce a lot of changes without explaining their scope and the expected outcome. This quickly caused many employees from different departments to complain about this situation directly to the firm's owner. This conflict came to a head within a couple of months. Despite the fact that it was very costly, the company's owner decided to terminate the contract with the said consultant as requested by the whole team, as otherwise the company would face the resignation of many crucial employees. A similar situation, although of a lesser scale, happened again with the employment of the new IT manager. With respect to the company's development, he recruited several new employees who had been working for his former employer. One of them behaved just like the British consultant. His knowledge was indisputable, but his interpersonal skills were very poor. For example, he made it clear to the team he managed that the actual hierarchical position in the company structure reflects personal skills and abilities. As a result, this employee was offered another position, where his individual skills were much more important than cooperating in the team, and ultimately he was laid off.

The inability to work in a group is not only a managerial issue. Not every boss that has an unfavourable opinion about their employees is the cause of the problem. As the new production manager started his role, he had to objectively improve poor departmental quality performance indicators. At the time of carrying out the interview it was not possible to trace back what were the actual origins of the situation: for example, poor managerial skills of the former boss or poor recruitment policies. With high 
certainty these and other issues had had a mutually reinforcing effect on the team performance. Only after changing $75 \%$ of the staff and after precisely articulating goals and making available appropriate organizational tools, the wave of indolence, lack of engagement, and mistakes was stopped. The production team was re-born, and currently these employees enjoy much freedom and rarely make mistakes.

Also among office line employees there were some individuals whose behaviour was negatively influencing the team spirit. One of them was a particular employee who despite committing a lot of mistakes was given another chance and prolonged employment contract by their supervisor. However, this employee soon accused their boss of having committed bullying towards her and began to snoop on team members looking for their mistakes. All this resulted in the atmosphere in the team being so tense that most of employees announced they would collectively quit if this person stayed any longer.

The corporate culture of Home décor retailer, as is the case of every organization, is an ephemeral phenomenon. The extent to which it effectively facilitates the coexistence of a group of people in pursuing team and individual goals changes continuously. This dynamism is shaped by ongoing experiences, interactions, and the determination of the management and the team to interpret the formally and informally adopted values in a genuine way. The example of Home décor retailer simultaneously shows the strengths and the weaknesses of the relational business model. The ability to create working conditions that foster self-control and selfmotivation and make people engaged is arguably one of the core corporate success factors reflecting the RBV concepts of VRIO resources and dynamic capabilities. The difficulty in preserving this ability and in developing human resources poses a major challenge for a company that is temporarily enjoying its effects. The example of Home décor retailer shows that even single personnel decisions may heavily impact this ability and disperse human resources, which have up to now been providing its strength. It is exactly this ephemeral quality of internal relationships which makes it hard to empirically validate the leverage power of RBV, especially in quantitative research. The intermittent nature of this phenomenon often makes the position of yesterday's leaders quickly erode. Sometimes much quicker than the publishing cycle of scientific papers. 
Illustration 2. Large manufacturing company operating in the FMCG market*

\section{Interviewees}

1. Sales manager-traditional distribution channels, employment history: more than 5 years.

2. Sales manager-new distribution channels, employment history: more than 5 years.

3. Key account field manager, employment history: more than 5 years.

\section{General Corporate Profile}

"Large manufacturing company operating in the Fast Moving Consumer Goods market" (Large FMCG manufacturer) supplies numerous international markets with various cosmetic and food brands. In its sustainable development strategy the company emphasizes achieving a balance between economic outcomes and the ability to influence everyday human lives (consumers, employees, small suppliers) in a positive way as well as reducing its negative impact on the natural environment. The overview of the company's characteristics is given in Table 5.2.

\section{Main Focus of Illustration \\ Managerial Tasks}

\section{Description}

FMCG companies have been traditionally the largest advertisers using electronic media. The FMCG markets are characterized by immanent anonymity, which means that these companies need intermediaries to reach their end consumers. One opportunity for a direct dialog with their clients for such companies is social media. However, even if a great interactive platform, social media are not without disadvantages. For example, they are mainly a source of information about customer buying intentions but not actual buying behaviour. Such data is only available in teller systems and systems servicing loyalty programmes owned by retail chains.

Until recently, the cooperation with retailers has been carried out in line with the schema described in Illustration 3 (Pamapol). The FMCGcompanies have been trying to combine a marketing pull strategy (e.g., ongoing advertising) with a push strategy (e.g., sales representatives frequently visiting diverse types of intermediaries to mobilize them to participate in simple consumer and trade promotions). Nowadays the job of a 
Table 5.2 Overview: Large FMCG manufacturer

\begin{tabular}{|c|c|}
\hline $\begin{array}{l}\text { Number of direct } \\
\text { customers }\end{array}$ & Thousands and more \\
\hline Number of employees & Between 999 and 4999 \\
\hline Main market served & $\mathrm{B} 2 \mathrm{C}$ \\
\hline Main business focus & $\begin{array}{l}\text { Production with commerce structures, customer service and } \\
\text { augmented services }\end{array}$ \\
\hline $\begin{array}{l}\text { Polish classification of } \\
\text { business activities }\end{array}$ & Wholesale trade \\
\hline \multicolumn{2}{|c|}{ Dominant management style } \\
\hline $\begin{array}{l}\text { - strategic company } \\
\text { level }\end{array}$ & $\begin{array}{l}\text { Centralization of decisions in the hands of top management, } \\
\text { multiple layers of management, work standardization and } \\
\text { formalization, big organizational units }\end{array}$ \\
\hline $\begin{array}{l}\text { - operating } \\
\text { company level }\end{array}$ & $\begin{array}{l}\text { Decisions in the hands of multiple types of managers and highly } \\
\text { qualified specialists, big organizational units }\end{array}$ \\
\hline $\begin{array}{l}\text { Main perceived } \\
\text { success factors }\end{array}$ & $\begin{array}{l}\text { Highly qualified and engaged team, excellent corporate } \\
\text { reputation/very strong brand }\end{array}$ \\
\hline Competitive & Steady expansion in terms of sales or market share \\
\hline advantage indicators & Steadily ahead of competitors in terms of profits \\
\hline \multirow{2}{*}{ (in the last two years) } & Entered a new market \\
\hline & Steadily a sought-after employer \\
\hline
\end{tabular}

* Descriptive company name- the company representatives agreed to share information only on condition its name will not be revealed. For the same reason, the general corporate profile does not provide any particular facts and data. The illustration represents the opinions of white collar employees.

sales representative resembles more consulting services than short-term project management. In the case of big retail chains, such cooperation involves joint volume analysis and customer buying behaviour analysis that enables the launch of dedicated products or the introduction of advanced Supply Chain Management solutions (from sales prediction through to Just-in-Time supply).

Such a work environment demands adaptable decision making and handling based more on data analysis, intuition, and on-the-job experience than on reproducing learnt schematic procedures. This is a great challenge not only for the sales representatives, but even more for their supervisors. For more than a year, Large FMCG manufacturer has been implementing changes aimed at helping its managers move their focus from plain sales reports, controlling, and providing simple instructions to managing by observation, listening, and coaching. This change has been marked in a symbolic way by the transition from MS Excel sheets to the MS Word text processing editor in preparing employee assessment reports. 
The latter became more descriptive and oriented to soft skills as an alternative to 'hardline' KPIs.

Large FMCG manufacturer's managers of all layers make use of the help of external coaches, whose role is to develop their ability to listen and to understand people and their emotions (also based on psychological knowledge), to build trust and to adequately react to varied situations. The company acknowledges the role of the human psyche on their functioning in any social context and that one of the major sources of stress or irritation can be the direct supervisor. This is more than mere declarations: if required, the company offers its employees free-of-charge consultations with a psychologist.

In the course of said change management, a 70/20/10 work time breakdown of a manager has been proposed. According to this model, managers should devote most of their time to the individual development of their employees, $20 \%$ to issues concerning the whole team, and only the remaining $10 \%$ to directly discussing ongoing business tasks. Hence, at Large FMCG manufacturer, all meetings begin by discussing humanrelated issues, like their well-being, and barriers, problems, and challenges they face. Only afterwards comes the time to review the ongoing work, because the company assumes that the employees know what to do, and if they have problems they simply report them and are not afraid to ask for advice. By introducing the $70 / 20 / 10$ rule, the company hoped to change the perception of a manager primarily as a principal and controller towards the image of a leader and coach. Therefore, the main goal of a manager in Large FMG manufacturer is to make sure that their employees have motivation to work-not in an oppressive manner, but so that they bring out the best in themselves. Thanks to the development of their emotional intelligence and interpersonal skills, the managers are closer to their employees. They should reduce the dialogue-blocking distance and present a receptive and engaged attitude towards the people that have been entrusted to them. By fostering team spirit and positive one-to-one relationships, the employees should gain a broadly understood psychological comfort, starting with personal security and dignity and ending with the perception that they are not stuck in the company but that they keep on learning new things and finding challenges worth their endeavour. This, in the end, will advance them to the position of a valuable partner in customer relationships. 
Illustration 3. Pamapol S.A.

\section{Interviewees}

1. Marketing director, employee history: more than 19 years.

2. Sales director, employee history more than 20 years.

\section{General Corporate Profile}

Pamapol is \#2 in the Polish convenience food market. The product range the company offers also includes tinned food, pâtés, ready-to-cook soups, and preserved vegetables. Pamapol distributes products in traditional channels via wholesalers as well as directly supplying large retailer chains. The company builds up its position both by developing its own brands and by acquiring entities having a strong position in complementary market segments. Pamapol is also one of the biggest private brand convenience food supplier to leading retail organizations. The overview of the company's characteristics is given in Table 5.3.

\section{Main Focus of Illustration}

The impact of personal/informal relationships on business relations

Table 5.3 Overview: Pamapol S.A.

\begin{tabular}{|c|c|}
\hline $\begin{array}{l}\text { Number of direct } \\
\text { customers }\end{array}$ & Several hundred \\
\hline Number of employees & Between 250 and 999 \\
\hline Main market served & $\mathrm{B} 2 \mathrm{~B}$ \\
\hline Main business focus & Production with commerce structures and customer service \\
\hline $\begin{array}{l}\text { Polish classification } \\
\text { of business activities }\end{array}$ & Manufacturing \\
\hline $\begin{array}{l}\text { Dominant } \\
\text { management style }\end{array}$ & $\begin{array}{l}\text { Centralization of decisions in the hands of top management, } \\
\text { multiple layers of management, work standardization and } \\
\text { formalization, large organizational units }\end{array}$ \\
\hline Main perceived & Highly qualified and engaged team \\
\hline success factors & Technical excellence \\
\hline Competitive & Steady expansion in terms of sales or market share \\
\hline advantage indicators & Steadily ahead of competitors in terms of profits \\
\hline (in the last two years) & Entered a new market \\
\hline & Steady increase of employment \\
\hline
\end{tabular}




\section{Description}

With its own and associated brands, Pamapol has been an active player in the convenience food market for several years (although the history of the oldest brand owned by the company-Kwidzyń-dates from the year 1934). After the year 1989, the Polish FMCG retailing market underwent a general change. The dominant roles were seized by a large-scale retail chain and some of the biggest chains of the wholesale and semi-wholesale trade, which diminished the position of small local stores and wholesalers. The intensification of competition also forced smaller players to increased professionalization. The longitudinal presence of Pamapol's sales force has made it possible to make interesting observations showcasing the evolution that this market has undergone, also with regard to personal and business relations.

The specifics of sales representatives' work are that they maintain ongoing contacts, including face-to-face contact, with their clients. As a natural consequence, some intimacy and trust is built. In turn, the customer is more open for a dialogue and ready to take account of their suggestions, proposals, or even requests. However, according to Pamapol's observations, this personal influence seems to get weaker the more professional the client organization becomes. During the pioneering times when the contemporary retail market organization was only beginning to crystalize, a store or wholesale company owner was willing to place an order without conducting any market analysis-purely after an informal recommendation of the sales representative (e.g., "Take 10 palettes of product X, people will buy it for sure"). In over-the-counter selling shops, it was even profitable to maintain relations with particular personnel members. As these shop assistants were not anonymous to the end-consumers, they were willing to make recommendations in exchange for low-value gadgets, and thus they were contributing to meeting the sales targets. Nowadays, however, at least in the case of ready-made meals, having a good relationship with the decision-maker only enables them to be easily reached and to count on their attention, but it has no major influence on their decisions. In other words, if the market analysis based on statistically processed data does not indicate a chance of making good business, the only courtesy that the decision-makers will offer to the befriended sales representative is to give detailed feedback on why the offer is declined. Their position will not be significantly different than any other sales representative offering an unattractive proposal. 
Nonetheless, Pamapol managers still maintain that, in particular situations, personal, informal relationships may make a big difference. They link them, however, with more significant transactions. A good example is the history of contacts with a particular facility manager, whom the representatives of Pamapol have been meeting at industrial fairs, at informal dinners and at 'in-the-corridors talks'. Six years of such informal dialogue has finally brought a major transaction. Still, it should be assumed that this business was basically beneficial to both parties, and the long time that had passed before the customer decided to conclude it indicates that it was well though-out, not an emotional decision.

What links the behaviour of both smaller and larger companies' business partners is the professional procurement process. In contrast to the early times of Polish capitalism in the late twentieth century, the contemporary electronic analytical systems and the multi-criteria formal decisionmaking procedures in the $\mathrm{B} 2 \mathrm{~B}$ sector seem not to leave much room for personal relationships. This is, however, only an apparent change. Although the recommendations of Pamapol's sales representatives for novice shop owners were informal and intuitive, they must, however, have been generally beneficial to them. Otherwise their businesses would have deteriorated, which in the end would also have hit Pamapol. These relationships had always to be mutually beneficial, though the ways or tools to succeed in those times were simpler. Similarly, nowadays a personal relationship cannot make up for lacking business perspectives. Being aware of this, Pamapol started its own R\&D activities. Thanks to this it can offer products tailored to customer needs. A good example is meatballs in dill cream sauce, which Pamapol delivers to the biggest retail chain in Poland, 'Biedronka', whereas the standard product is offered in tomato sauce. A lack of willingness or possibility to change the product recipe would arguably have caused Pamapol to lose its important client despite good personal relations. By contrast, however, very good relationships among buyer and supplier representatives help to make the client aware of the firm's competences, to present product arguments, to learn about the motives, needs and client business specificity and, occasionally, to benefit from personal preference, provided the alternatives offered by the competitors are comparable.

To sum up one can say that, from Pamapol's managers' perspective, the most important issue in $\mathrm{B} 2 \mathrm{~B}$ relations is the ability of the supplier to jointly co-create attractive value with its clients. Lacking good personal relationships may, however, delay or even disallow the development of 
tighter cooperation, because the customer will not recognize its potential. In contrast, in the case of temporarily lacking the ability to propose attractive cooperation, the openness for communication will help the supplier in precisely identifying its own weaknesses. The relationship capabilities are, therefore, one of the core corporate competences.

Illustration 4. Medium manufacturing company representing chemical industry*

\section{Interviewees}

1. Member of the executive board, employment history: 15 years; simultaneously acting executive board member in other enterprises and industrial associations, and executive boards' advisor.

\section{General Corporate Profile}

Several decades have passed since the foundation of 'Medium manufacturing company representing chemical industry' (Chemicals' manufacturer). During that time the company has become the industry leader, distributing its products to numerous international markets. The company is active mainly in the automotive and building sectors. It has its own brands dedicated to various market segments and develops its own technologies. The overview of the company's characteristics is given in Table 5.4.

\section{Main Focus of Illustration}

Personal relations between high-ranked executives in the B2B markets

\section{Description}

Manufacturing companies generally believe that the success of a company is mainly shaped by the ability to deliver a good product in a good price. Nowadays, in many industries, this still remains the basic though not sufficient requirement. The differences among basic product/price characteristics are so narrow that the development of a company and acquiring new customers are (according to the quoted interlocutor) only enabled by personal relations. However, this is not about shallow ad hoc contacts, but a long-term, sincere relationship. From the business point of view, the actual content of such relationships is the ability to get access to undisclosed information. In the end, it all comes down to customer needs definition-needs that could be satisfied by many potential suppliers, if they knew the broader context of customer decision-making. Without such 
Table 5.4 Overview: Chemicals' manufacturer

\begin{tabular}{|c|c|}
\hline $\begin{array}{l}\text { Number of direct } \\
\text { customers }\end{array}$ & Several hundred \\
\hline Number of employees & Between 50 and 250 \\
\hline Main market served & $\mathrm{B} 2 \mathrm{~B}$ \\
\hline Main business focus & $\begin{array}{l}\text { Production with commerce structures, customer service and } \\
\text { augmented services }\end{array}$ \\
\hline $\begin{array}{l}\text { Polish classification } \\
\text { of business activities }\end{array}$ & Manufacturing \\
\hline $\begin{array}{l}\text { Dominant } \\
\text { management style }\end{array}$ & $\begin{array}{l}\text { Centralization of decisions in the hands of top management, } \\
\text { multiple layers of management, work standardization and } \\
\text { formalization, large organizational units }\end{array}$ \\
\hline $\begin{array}{l}\text { Main perceived } \\
\text { success factors }\end{array}$ & Highly qualified and engaged team \\
\hline Competitive & Steady expansion in terms of sales or market share \\
\hline $\begin{array}{l}\text { advantage indicators } \\
\text { (in the last two years) }\end{array}$ & Entered a new market \\
\hline
\end{tabular}

intelligence they can only compete on quality and price of the standard offer, and on some additional blindly chosen supplementary arguments, which sharply reduces their chances of success.

Meanwhile, in order to co-create substantial value with the customer, their openness and attention is needed. In this context, the attitude of the leaders on both sides is very important including their mutual attitudes, interpersonal skills, and value systems. If they can communicate sincerely and place their trust in each other, their talks will be effective and they can quickly move joint ventures forward. An example of such transparency could be the supplier quickly reporting that the requested technical or financial boundary conditions cannot be met because of concrete, factual reasons that the final combined product recipient (the client of the client) might have not been aware of. An alternative could be an attempt to formally meet these requirements, but at the cost of some compromise (e.g. with regard to quality) that the final product recipient did not foresee or such that would not have been possible to verify.

Certainly, not every business opportunity leads to direct contacts of top executives. In general, the greater the disproportion between the companies, the harder it is to establish such a connection. Larger organizations are also usually less flexible because of the structural and processual costs 
of servicing (what they assess as) niche markets, needs, and processes. This gap is bridged by specialized middlemen. These very well connected individuals can be labelled 'relationship brokers'. They are usually experienced managers, who retired after a long service in multinational companies and influential industrial bodies and who still observe the market from close up. Owing to this, they analyse industrial trends, planned investment and the motives of decision makers to effectively connect people, firms and projects. Being 'relational know-how masters', they offer their knowledge and advice to firms whose relationship capital is insufficient to become a recognized business network member on their own.

To conclude, one can say that the business practice of Chemicals' manufacturer contradicts the view that the transparency of the institutional markets precludes the possibility to effectively use personal relations for business purposes. First, only products based on some industry standards are fully transparent, but not dedicated solutions that have to be co-developed with the customer. Second, personal relationships seem to be equally important in $\mathrm{B} 2 \mathrm{~B}$ and $\mathrm{B} 2 \mathrm{C}$ markets provided the relationship is established between individuals, who treat themselves as partners and possess the authority to take binding decisions in the given business case. Even if the decision-making process in the $\mathrm{B} 2 \mathrm{~B}$ setting is more complicated and more professional, the decisions are taken in bounded rationality, which causes risks that can be intuitively mitigated by trusted partners.

Illustration 5. Konimpex-Invest Sp. z o.o

\section{Interviewees}

1. General director, employment history: more than 5 years.

2. Manager of customer service office, employment history: more than 5 years.

\section{General Corporate Profile}

Konimpex-Invest is a medium real estate developing company that has been operating in Poznań and Konin areas for 15 years. The company coordinates the building activities of several real estate investments, mainly targeted at individual clients. This implies that the company does not manage its own building teams, but focuses on searching and purchasing attractive construction land, giving guidelines and placing orders for architectural plans that should cater to contemporary customer needs, and supervising construction works. In addition, Konimpex-Invest offers administration services in own-built estates via its associated company. 
Table 5.5 Overview: Konimpex-Invest Sp. z o.o.

\begin{tabular}{|c|c|}
\hline $\begin{array}{l}\text { Number of direct } \\
\text { customers }\end{array}$ & Several hundred \\
\hline Number of employees & Between 10 and 50 \\
\hline Main market served & $\mathrm{B} 2 \mathrm{C}$ \\
\hline Main business focus & Commerce, customer service and augmented services \\
\hline $\begin{array}{l}\text { Polish classification of } \\
\text { business activities }\end{array}$ & Construction \\
\hline $\begin{array}{l}\text { Dominant management } \\
\text { style }\end{array}$ & $\begin{array}{l}\text { Decisions in the hands of multiple types of managers and } \\
\text { highly qualified specialists, large organizational units }\end{array}$ \\
\hline Main perceived success & Highly qualified and engaged team \\
\hline factors & Excellent corporate reputation/very strong brand \\
\hline Competitive advantage & Steady expansion in terms of sales or market share \\
\hline indicators & Steadily ahead of competitors in terms of profits \\
\hline (in the last two years) & Steady increase of employment \\
\hline & Steadily improving customer loyalty rate \\
\hline
\end{tabular}

The company is part of Konimpex capital group, which operates in diversified industries. The parent company has been specializing in the trade of raw materials and industrial and chemical components for 30 years. In addition, the group consists of Konimpex-Plus (outdoor clothing and equipment distributor), Konimpex Trading (facilitating trade between Poland and Uzbekistan), and publishing house "Przegląd Koniński"—a publisher of three regional magazines. The overview of the company's characteristics is given in Table 5.5.

\section{Main Focus of Illustration}

Barriers to developing relationships with customers and suppliers

\section{Description}

Theoretically, companies in the real estate development industry have a superior starting position for customer relationship management. Direct access to customers, very high value of transactions and their emotional importance make them open to non-anonymous contacts via varied communication channels. What is, however, somewhat problematic, is the repeatability of transactions. According to varied sources, an average Pole changes accommodation 2-5 times in a lifetime (however, no research is available that would differentiate between changing to a new or preowned flat (Badowski 2017; Polskie Radio 2014)). Buying an apartment from the same developer again is therefore unlikely. This places contacts 
with companies such as Konimpex-Invest more in a transactional than a relational context. Naturally, a real estate company cannot afford to deliver a poor quality apartment or to break given promises (e.g. failing to build a playground once the building is ready). Nonetheless, in the case of most customers, carrying out the proactive elements of CRM strategy does not apply in the after-sales period when, owing to a very distant prospect of buying an apartment again, customer interest in maintaining contact with the company falls dramatically. Also, possible referrals will be based rather on the material elements of the offer (apartment) than on after-sales contacts with the company.

Nonetheless, Konimpex-Invest found a way to widen the spectrum of relational cooperation with its customers. Being aware of the fact that the actual possibility to engage the customer in a relationship cumulates in the period before the apartment is handed over, the company proposes a programme called 'Reciprocal package'. It is aimed at motivating customers towards activities benefiting the company in exchange for financial allowance in the form of free of charge transfer of the apartment ownership rights. 'Reciprocal package' is based on a points system. Half of these points are granted for using the add-on services Konimpex-Invest provides (e.g. mortgage and finishing works intermediation). The other half is linked with activities on social media: leaving positive comments on the company's Facebook fan page and providing a recommendation on Facebook or Google maps.

The said programme does not impact long-term relationship management. However, the second initiative of Konimpex-Invest does. Most clients are looking for a new flat for themselves. However, there is a tiny group of people who buy new apartments with the intention to rent them. Many of these individual investors have built private real estate portfolios, which creates the potential for mutual long-term cooperation. Even if the main substance of the transaction is the apartment, the emphasis is placed on after-sales services. With regard to service logic, the duration and profitability of the relationship is mainly shaped by the extent that the company enables its customers to unfold their real estate investment strategy without having to be personally involved in the renting activities. Hence Konimpex-Invest, via its partner company, offers convenient services ranging from financial bookkeeping to full legal, technical, and maintenanceadministrative services.

Overcoming the barriers of the transactional business model with the help of a selective relational strategy and the servicization of the offer 
indicates an advanced approach to RM. Nonetheless, the transactional logic dominates not only in the case of the bulk of the individual clients, but also towards the company's suppliers. Konimpex-Invest purposefully does not develop strategic relationships with any of the construction companies because it assesses that exploiting the full potential of a given construction project is much more probable if it is separately negotiated each time. Such an approach is exemplified in periodical change of analysts assessing the offers and of frontline personnel directly contacting the construction companies. Konimpex-Invest does this to avoid personal acquaintance impacting the professionalism of the tender assessing process.

Moreover, it is a rule of thumb to cooperate with multiple construction companies even if the finished investment projects are highly satisfactory. Such a policy is dictated by the logic of tender offer procedure. Although, as a private investor, Konimpex-Invest does not have to select based on the lowest price, the company expects to receive competitive offers. However, owing to the fact that preparing such an offer is very time-consuming and costly, the construction companies carefully analyse the likelihood of gaining the contract before they decide to begin to tender. If one company kept winning all tenders organized by Konimpex-Invest, it would soon only be this offerer that would stand for the next tender, which could heavily impact its pricing policy.

The same logic is reproduced in the sugar market (compare Illustration 7), where the main buyers purposefully divide their orders so that no supplier gains the upper hand and in the case of Termy Maltańskie (Illustration 6), although this time the market is being intentionally divided not by the buyer, but by the supplying companies. The example of Konimpex-Invest and these firms indicates that relational-based competitive advantage mainly emerges when there exists room for joint individualized value cocreation. In such a case one can assume that the market is best coordinated by managing relationships. However, if the potential for co-creating individualized value in a long-term relationship is unlikely or it mainly depends on the buyer (so that the buyer could achieve a comparable effect with any partner), relational cooperation loses ground as the most effective market coordination method. This may be one of the reasons for the difficulties hitherto in proving the positive assumptions of RBV. Corporate resources may be relatively valuable, rare, inimitable, and organized so that the company holds a strong position among the limited number of market leaders and simultaneously still too generic to achieve absolute dominance. 
Illustration 6. Termy Maltańskie Sp. z o.o

\section{Interviewees}

1. President of the executive board, employment history: more than 5 years.

2. Executive board member, employment history: more than 5 years.

\section{General Corporate Profile}

Termy Maltańskie is the biggest waterpark in Poland and the third biggest in Europe. The company is fully owned by the municipality of Poznań. The facility was put into service in 2011 and its development was listed as one of the key investments coordinated with the European Football Championships UEFA EURO 2012, for which Poznań was one of the hosting cities. The facility contains recreational and sports swimming pools and a sauna zone, which are visited by 1.2 million guests annually (based on data from 2019; COVID-19 crises brought sever losses in guest numbers in 2020). The complex holds several cooperating companies including swimming school, fitness, dance school, and restaurant. The overview of the company's characteristics is given in Table 5.6.

\section{Main Focus of Illustration}

Supplier-buyers Relationships

Table 5.6 Overview: Termy Maltańskie Sp. z o.o.

\begin{tabular}{|c|c|}
\hline $\begin{array}{l}\text { Number of direct } \\
\text { customers }\end{array}$ & Thousands and more \\
\hline Number of employees & Between 50 and 250 \\
\hline Main market served & $\mathrm{B} 2 \mathrm{C}$ \\
\hline Main business focus & Services with commerce structures \\
\hline $\begin{array}{l}\text { Polish classification of } \\
\text { business activities }\end{array}$ & Other services \\
\hline $\begin{array}{l}\text { Dominant management } \\
\text { style }\end{array}$ & $\begin{array}{l}\text { Democratic decisions resulting from the opinions of many } \\
\text { employees, small organizational units and matrix structures. }\end{array}$ \\
\hline Main perceived success & Highly qualified and engaged team \\
\hline factors & Convenient localization \\
\hline $\begin{array}{l}\text { Competitive advantage } \\
\text { indicators }\end{array}$ & $\begin{array}{l}\text { Steady expansion in terms of sales or market share } \\
\text { Steadily ahead of competitors in terms of profits } \\
\text { Steadily improving customer lovalty rate }\end{array}$ \\
\hline
\end{tabular}




\section{Description}

One of the priorities for a company offering leisure time spending in water is safety. Among many facets of this problem, which include such issues as the technical reliability of facilities and their proper maintenance and cleanliness, the number of lifeguards and their training seems to play the most important role. Despite the fact that the said service is rather uncomplicated (many young people earn a lifeguard licence after attending an one-week course and passing the exam), in a business context it bears high risk, which has to be reduced, especially by a publicly-owned company. For its management, every case of drowning, even if all official rules were followed, would be highly likely to end in having an argument with the public on potential additional safety measures that might have saved a human life.

Owing to this, whatever investment in security the company would allocate (e.g. hiring additional lifeguards) could be seen as insufficient. Therefore, a more effective way of elevating the level of security is to share this risk with a specialized partner. A lifeguarding company is responsible for the recruitment, required licences, training level, and the general work attitude of its employees. It has to guarantee that enough personnel will be available even in the summertime, when the demand for lifeguarding increases sharply. The additional specificity of Termy Maltańskie is that, as a publicly-owned company, it is obliged to follow the rules of Public Procurement Law, if the annual worth of products or services of the same kind exceeds 30,000 EUR. Following this, Termy Maltańskie has to carry out complex tendering procedures, inter alia, for lifeguarding services.

Theoretically, the party that purchases products or services has an advantage over the supplier, at least until the transaction is concluded. The buyer can exert pressure on the supplier, and if the offered conditions are not satisfactory, they may well choose another one. This is a classical imbalance of contracting parties, which heightens the more competitive the market and the more generic the offer at stake. A public tender is a tool that mostly takes into account the price, and therefore it follows the transactional logic of doing business. On the other hand, lifeguarding service providers are aware of their critical importance for big waterparks, and they have become experts in public tendering. This has allowed the relationships among the big lifeguarding firms to flourish.

The tendering process is expected to create transparency and optimize public funds disbursement. However, according to the practice of Termy Maltańskie and other similar firms, these objectives are, at least partly, not 
met. In order to meet the strict safety regulations, waterparks have to set rigorous requirements, which allow them to formally accept an offer for further detailed examination. However, this reduces the number of potential service providers to only a few of the largest ones in Poland. As this situation has repeated again and again, a quasi-monopoly in the niche of lifeguarding services for large facilities has emerged.

A closer look at the pattern of behaviour of large lifeguarding companies brings similar observations. One of them places a dumping offer, another an expensive one and the third one the offer with a targeted price level. Initially, the lowest-price logic favours the first offer, which is, however, placed only in case an unexpected competitor emerges. As soon as the list of offers is closed and there is no such danger, the lowest offer is withdrawn, and the tendering is won by the 'third' company. The offer with the highest price acts as the background for the whole tendering process, so that it cannot be annulled. This schema is being reproduced elsewhere across the country. The only difference is the changing roles of the companies.

The collusive behaviour of the three companies is most evident. It is simultaneously proof of managing relationships-even if not, as usual, with customers, but with competitors. So it seems, a company does not necessarily have to adopt a total RM strategy. This means that the relationship management capability with some actors does not exclude adopting a transactional strategy towards others. RM is, therefore, not a 'natural strategy', which will prevail once the external and internal barriers of its implementation are overcome. A healthy business relationship is only possible when the partners of the relationship have a free choice and maintain comparable positions, and the more likely this is, the higher the chance for synergistic added value generation.

Interestingly, by imposing the transactional logic of tendering to prevent the relationships between the representatives of buyer and seller going against the interest of the tax payer, the legal regulations have, in fact, undermined the position of the publicly-owned company. However, arguably, in the given circumstances, also the classical invisible hand of the market' would probably also not guarantee a better outcome, because the rent resulting from the collusive relationship seems to be higher than the theoretical rent resulting from unforced customer loyalty-making. Paradoxically, the intervention of the state would be most welcome-not in the form of tendering but in effective anti-cartel regulations. 
Simultaneously, although RBV clearly describes the intra-company mechanism for generating sustained competitive advantage based on VRIO resources and dynamic capabilities, the example of Termy Maltańskie indicates that business performance may be strongly affected by the external market forces described by M. Porter (1979). In the case of the lifeguarding services' market, the bargaining power of suppliers and buyers is balanced, as there are few of them on either side. The substitute for outsourcing of lifeguarding services is organizing these services by the waterparks themselves, which, owing to the highlighted risks is not a comfortable option. The industry rivalry is not intense, because of mutual relationships and shared market servicing strategy, which is directed to minimize the threat of new entrants (by applying the mechanism of the dumping offer). Hence, even if lifeguarding is a generic service, the threat of new entrants is also not acute, which, in the end, stabilizes the market structure.

Illustration 7. Sugar-refining group*

\section{Interviewees}

1. Finance Manager, employment history: more than 5 years.

2. Sales Manager, employment history: more than 5 years.

\section{General Profile}

Sugar-refining group is a European sugar manufacturer present in 18 countries. The company (the first sugar refinery) was found in nineteenth century by several small investors in Germany. The company generates $60 \%$ of its turnover in the market of big consignees, such as manufacturers of sweets and soft drinks. In addition, it owns sugar consumer brands. Sugar-refining group holds the strongest position in northern Europe. In Poland it belongs to the group of the three biggest sugar manufacturers. The overview of the company's characteristics is given in Table 5.7.

\section{Main Focus of Illustration}

The influence of competition and unfavourable market conditions on the importance of customer relationship management.

\section{Description}

Not long ago the sugar market on the territory of the European Union was fully regulated. In 2012 the price regulation was lifted, and in 2017 the production limits were also lifted. The result was sharp price 
Table 5.7 Overview: Sugar-refining group

\begin{tabular}{ll}
$\begin{array}{l}\text { Number of direct } \\
\text { customers }\end{array}$ & Several hundred \\
$\begin{array}{l}\text { Number of employees } \\
\text { Main market served } \\
\text { Main business focus }\end{array}$ & $\begin{array}{l}\text { Between } 999 \text { and } 4999 \\
\text { Production with commerce structures, customer service and } \\
\text { augmented services }\end{array}$ \\
$\begin{array}{ll}\text { Polish classification } \\
\text { of business activities }\end{array}$ & $\begin{array}{l}\text { Manufacturing } \\
\text { Dominant }\end{array}$ \\
management style & $\begin{array}{l}\text { Centralization of decisions in the hands of top management, } \\
\text { multiple layers of management, work standardization and }\end{array}$ \\
$\begin{array}{l}\text { Main perceived } \\
\text { success factors }\end{array}$ & $\begin{array}{l}\text { Highly qualified and engaged team } \\
\text { Excellent corporate reputation/very strong brand }\end{array}$ \\
$\begin{array}{l}\text { Competitive } \\
\text { advantage indicators } \\
\text { (in the last two years) }\end{array}$ & \\
\hline $\begin{array}{l}\text { * Descriptive company name-the company representatives agreed to share information only on condi- } \\
\text { tion its name will not be revealed. }\end{array}$
\end{tabular}

fluctuations from a record high of approximately $600 \mathrm{EUR} /$ tonne to very low $250 \mathrm{EUR} /$ tonne - as the interview was being held. This situation was influenced by the expansion of sugar production area across EU-countries and very good sugar beet crops in the European Union and sugarcane harvests in Brazil. This heavily affected the financial outcomes of sugar manufacturers, because they usually rely entirely on selling sugar and its low-processed products (e.g. special sugars like sugar with cocoa and powdered sugar). The knock-on effect was fierce competition that was reflected by the willingness to ship sugar over large distances. Up to this point a relatively stable market allocation was cultivated, which was sanctioned by the long tradition and the high costs of shipping sugar in relation to the shipment value.

Sugar-refining group identifies three main client groups:

- food manufacturers,

- retail sugar distributors in the markets, where the company maintains geographically-based competitive advantage,

- sugar distributors in export markets. 
The portfolio of the key clients from the first group has been stabile for years. This is not due to long-term contracts (these are usually signed annually), but because of:

- market price transparency (sugar is traded on commodity exchanges, therefore the buyers may easily negotiate a satisfactory price without having to change supplier);

- the policy of the key buyers, who divide their orders across two or three suppliers (so that none of them would get a dominating position).

It seems that the policy of balancing the market is very important for the major sugar buyers. A good example of how this policy is being implemented can be seen in the situation of a particular food manufacturing facility, which is situated a couple of miles from the sugar refinery and yet it purchases only a part of the required sugar quantity there. The rest is supplied by refineries owned by the other sugar corporations, even if the shipping costs are much higher.

Being an established market player, Sugar-refining group has always relied on the principle of maintaining long-term customer relationships. However, the sugar oversupply crisis has made it clear to the company's management that even if cooperation with the food manufacturers is of mutually strategic importance, Sugar-refining group's impact on the value creation processes of its clients is marginal. It is entirely based on one homogenous product and, as purchasing managers from food industry say: "sugar remains sugar". Therefore, the relations Sugar-refining group holds with these clients can be characterized in the following way:

- it is important with regard to transactional volume, but of low intensity and generally maintained by necessity;

- it is heavily shaped by exogenous factors;

- it is marked by the advantageous position of the buyers, who make use of sugar price transparency and 'regulate' the market, only expecting that the supplier react to the required demand.

In the case of the second group of clients-the retail sugar distributors located in the markets where Sugar-refining group maintains a geographically-based competitive advantage, the oversupply of sugar has also impacted the margins of the company, even if the costs of shipping 
sugar from Western or Central Europe via the Baltic See or Danish Straits moderately stabilized the price reduction. On the other hand, the crisis has made it evident that also in the case of these clients, the stability of business relationship is generally exogenically-based, and the only tangible effect of the strategic partnership with the retailing distributors are the 'innovative' special sugars, which remain low-processed products. That is why in countries such as Poland, where there are several major sugar suppliers, the retailing distributors do not develop strong exclusive ties with any of them, especially owing to the fact that they usually sell sugar under their private labels. Probably the only way of taking advantage of relationship rent by sugar manufacturers remains on the basis of individual relationships between the employees of the buyer and supplier. However, this mainly translates into an information advantage, but not to ultimate buying preference. Moreover, many retailing distributors keep on changing the areas of responsibilities of their purchasing staff to minimize what they perceive as the risk of bribery.

To sum up, one can state that longitudinal relationships in a market of limited competition where a low-processed, homogeneous, non-innovative product is traded is not a proof of relationship maturity. In the case of Sugar-refining group and similar companies, the longstanding relative market stability have clouded their capability to further develop relationships and left their clients in a state of (probably) partly unmet or unconscious needs.

The supply shock has made Sugar-refining group start concept work on ways to develop its competitive position in the new market conditions. One of these ways is to further expand by taking over sugar refineries from areas where the company currently does not hold a dominant position. Another relies on looking for innovative products based on the special sugars developed for the northern markets. The goal of the third one is to increase the share of services in its portfolio so that Sugar-refining group can advance to a more strategic position in the value creation process of its main clients. Currently the potential for improving the level of services already offered is being evaluated as well as new services being conceptualized. A good example of such a new service may be the improvement in flexibility of sugar supply, so that the order is delivered within 24 hours from ordering. Also important is making both their own sales representatives and the clients aware that even today the company is offering some add-on services which allow them to positively differentiate their offer against competitors (e.g. free of surcharge weekend sugar deliveries). 
As the example of Sugar-refining group and some of the previous illustrations show, despite declaring overly positive relationship values like responsibility and engagement, the relational model of company development is not more natural or probable than strategizing in the manner of M. Porter's five forces model, at least when it comes to generic products. Moreover, if possible, these markets will rather motivate the suppliers to strive for achieving some state of monopoly by showing all the external signs of willingness for partnership, however being reduced to the mere desire to have a stable buyer. On the other hand, the buyers will try to maintain as much flexibility and freedom of decisions as possible, which is, in fact, likely to leave mutual relations on the transactional level.

Illustration 8. Aquanet S.A.

\section{Interviewees}

1. Senior customer care specialist, employment history: more than 5 years.

2. Manager of customer care department, employment history: more than 5 years.

\section{General Corporate Profile}

The company offers water and wastewater services for the Poznań area and for neighbouring municipalities populated by approximately 900,000 customers. More than $70 \%$ of the company's shares are owned by the city of Poznań, the rest by other municipal authorities. The Aquanet capital group includes several entities that are subcontractors to parent company. Examples of their services include: design and construction of new water and wastewater network, maintenance and breakdown removal, and water quality surveillance. The overview of the company's characteristics is given in Table 5.8.

\section{Main Focus of Illustration}

Formulation of relational targets under the conditions of a natural monopoly

\section{Description}

The idea of the complex implementation of a relationship approach is relatively new to Aquanet. For decades the company has been concentrating mainly on technical, engineering operations. The changes in the 
Table 5.8 Overview: Aquanet S.A.

\begin{tabular}{ll}
\hline $\begin{array}{l}\text { Number of direct } \\
\text { customers }\end{array}$ & Thousands and more \\
$\begin{array}{l}\text { Number of employees } \\
\text { Main market served }\end{array}$ & Between 250 and 999 \\
$\begin{array}{l}\text { Main business focus } \\
\text { Polish classification } \\
\text { of business activities }\end{array}$ & Services \\
$\begin{array}{l}\text { Oominant } \\
\text { management style }\end{array}$ & $\begin{array}{l}\text { Centralization of decisions in the hands of top management, } \\
\text { multiple layers of management, work standardization and }\end{array}$ \\
$\begin{array}{l}\text { Main perceived } \\
\text { fuccess factors }\end{array}$ & $\begin{array}{l}\text { Excellent corporate reputation/very strong brand } \\
\text { Wompetitive }\end{array}$ \\
$\begin{array}{l}\text { Weak, dispersed or non-existent competition } \\
\text { advantage indicators }\end{array}$ & Entered a new market \\
(in the last two years) & \\
\hline
\end{tabular}

company's environment (e.g. the coordination of activities of municipal companies to serve the overall policy of the city of Poznań) and the professionalization of general corporate management has brought numerous initiatives, whose general aim was to increase the maturity of relationship management with Aquanet's stakeholders. The situation of the company is, however, specific. Owing to its public service mission and municipal ownership, the company was in position to set the goal of elevating customer satisfaction, however without linking it with improved financial results. Aquanet cannot actively follow a sales increase objective (except for the extensive expansion of water and wastewater network). On the contrary, the company should get its clients to save water. A revenue increase might be achieved by cross-selling add-on services; however the primary goal would have to remain entirely focused on facilitating customer activities when connecting to the network or operating connecting pipes, not on generating additional income. Hence, the RM business case cannot be based on revenue increase. In contrast, the motivation to increase customer satisfaction is somewhat dimmed by their indifference. The majority of the company's customers only expect that their taps provide water, without needing closer relationships with the supplier. Therefore, most of Aquanet's proactive consumer activities take a form bordering on public relations and corporate social responsibility.

The aim of these activities is broadly defined as education and fun. Some of the events organized by Aquanet are relatively loosely linked with 
company's core business area. The company acts here as a sponsor supporting activities financed and organized by the city of Poznań. The examples of such initiatives include, for example, patronage over theatre performances organized in the City Hall courtyard and partnering nongovernmental organizations. Activities directly linked to water are, of course, present including ecological education and influencing consumer attitudes towards water saving and reducing water waste.

Arguably, the highest potential for improving both customer satisfaction based on direct contacts with the company as well as its financial results can be linked with the activities focused on Aquanet's employees. These activities can be divided into two groups: general culture formation and internal process optimization. The company impresses with a persistent determination in the evolutionary transformation from a 'divide and rule' corporate culture into an effective relational culture. This is confirmed, inter alia, by the fact that the aforementioned CSR activities are implemented with reference to the sustainable development and responsible business strategy for 2017-2022, which was prepared with the active involvement of Aquanet's employees. This was a logical step, which followed the earlier development of a system of corporate values aimed to govern the activities of every employee, irrespective of work history and position, and the Book of Customer Servicing Standards, which regulates the approach to external relations.

The implementation of the new values and standards was backed by a training programme aimed in making employees familiar with the content and meaning of these changes. New training proposals, such as stress management and team management, were also introduced. The selected employees got feedback on their strengths, weaknesses, and possible selfdevelopment during special sessions. In addition, managers participated in training on employee-development interviewing. Later, a Code of Ethics was prepared to promote cultivating the adopted corporate values among both employees and Aquanet's business partners. Compliance with the Code of Ethics is supervised by the Ethics Committee. All these initiatives do not exhaust the necessity for further work. At the point when this illustration was prepared, Aquanet finds itself in the transition phase from transactional to relational management.

Low employee turnover and the longstanding employment history of most employees (which is generally positive) suggest that the corporate memory stores the behaviours and attitudes embedded in earlier times. If these characterize the majority of employees of a particular organizational 
unit and, above all, its boss, they may be reproduced and adopted by newcomers. Such a silent, not entirely intentional resistance to change may persist and negatively influence the corporate culture for a long time. In turn, any culture change remains superficial and requires ongoing external engagement, because the intra-departmentally projected mode of behaviour will be still different than expected.

What also challenges the company's change management programme is ineffective internal organizational processes preserved by a complex IT infrastructure. Hence, a durable and fundamental advancement toward RM maturity will only be possible once all the processes are mapped (what has already taken place), optimized, and digitalized by new integrative IT tools. The company's transformation will be completed once the processual and technical change enables it to confer responsibility, knowledge, and authority to line employees.

The processual change has also opened the door to achieving work effectiveness-based financial benefits. Simplification of procedures reflected in their reduced labour-intensity and time-consumption, as well as the improvement in internal communication, will not only positively influence internal and external customer satisfaction but will also pay off in reduced costs. Cutting red tape by simultaneously ensuring the transparency of the outputs of business processes should enable the company to fully unlock the potential hidden in individual employees and in whole teams. This, in turn, enables fully meeting the implicit customer service standards (not possible for detailed regulation and controlling) and evoking entrepreneurial (innovative) attitudes among employees.

To sum up, the example of Aquanet shows a particularly important pattern. The benefits linked to RM maturity can be realized even by organizations which, due to multiple barriers in their environment, cannot directly benefit from relationship rent obtained with their external partners. However, the quality of internal relationships is not always reflected in low employee turnover (as an equivalent for customer loyalty), because they may be based by stagnation and reduced expectations. Simultaneously, even if the company remains in an advantageous position towards its partners (in the case of Aquanet, towards customers), a change aimed at improvement in their satisfaction (reflected at least in reduced time to generate the expected servicing outcome) may positively impact corporate effectiveness. In the end, the foundations for cost reduction-based competitive advantage are laid, and simultaneously the ability to react to new external stimuli is improved. Such a resilience mechanism may be 
activated, for example, in the case of market deregulation or new market entry (the relationship capital stabilizes customer outflow) or when new market opportunities emerge (the ability to react quickly thanks to resource potentiation). Another type of argument for developing a relationship approach to business may also be the golden rule prevalent in almost all the world's religions and cultures: "treat others as you would like to be treated" (Reichheld and Markey 2011, p. 13). Creating a better company does not cost more than a worse one. Simultaneously, a better company positively impacts the environment and the lives of many people and makes the world a better place to live.

\section{Notes}

1. NPS is calculated by subtracting the percentage of Detractors (customers who answered the question 'How likely is it that you would recommend [brand] to a friend or colleague?' by giving scores 0-6) from the percentage of Promoters (customers who answered the same question by giving scores 9-10). Customers who answered the same question by giving 7-8 scores are treated as Passives and their scores are not calculated. NPS can range from -100 (if every customer is a detractor) to a +100 (if every customer is a promoter).

2. The label 'transaction-oriented company' is given to separate the rest of the companies from the RM-mature ones in the upcoming models of market competition. As already indicated in Chap. 2, these companies do not have to represent a homogenous group and they may even define themselves as RM-oriented. However, given the totality of the RM-maturity model, by all possible diversity of actions and approaches, they have one thing in common: they do not generate a relational rent.

\section{REFERENCES}

Ahearne, Michael, John Mathieu, and Adam Rapp. 2005. To Empower or Not to Empower Your Sales Force? An Empirical Examination of the Influence of Leadership Empowerment Behavior on Customer Satisfaction and Performance. Journal of Applied Psychology 90 (5): 945-955. https://doi. org/10.1037/0021-9010.90.5.945.

Ahn, Jae-Hyeon, Sang-Pil Han, and Yung-Seop Lee. 2006. Customer Churn Analysis: Churn Determinants and Mediation Effects of Partial Defection in the Korean Mobile Telecommunications Service Industry. Telecommunications Policy 30 (10): 552-568. https://doi.org/10.1016/j.telpol.2006.09.006. 
Badowski, Artur. 2017. Dlaczego i Jak Często Się Przeprowadzamy? Strefa Biznesu. https://strefabiznesu.pl/dlaczego-i-jak-czesto-sie-przeprowadzamy/ ar/c3-11719258

Barner, Robert. 1994. Enablement: The Key to Empowerment. Training \& Development 48 (6): 33-37.

Bharadwaj, Sundar G., P. Rajan Varadarajan, and John Fahy. 1993. Sustainable Competitive Advantage in Service Industries: A Conceptual Model and Research Propositions. Journal of Marketing 57 (4): 83-99. https://doi. org $/ 10.2307 / 1252221$.

Buttle, Francis, and Stan Maklan. 2019. Customer Relationship Management: Concepts and Technologies. London: Routledge.

Chatterjee, Sayan, and Birger Wernerfelt. 1991. The Link Between Resources and Type of Diversification: Theory and Evidence. Strategic Management Journal 12 (1): 33-48. https://doi.org/10.1002/smj.4250120104.

Chatterjee, Sheshadri, Soumya Kanti Ghosh, Ranjan Chaudhuri, and Bang Nguyen. 2019. Are CRM Systems Ready for AI Integration? A Conceptual Framework of Organizational Readiness for Effective AI-CRM Integration. The Bottom Line 32 (2): 144-157. https://doi.org/10.1108/ BL-02-2019-0069.

Comer, Michael J. 1998. Corporate Fraud. 3rd ed. Burlington: Gower Publishing, Ltd.

Dalgic, Tevfik. 1998. Niche Marketing Principles: Guerrillas versus Gorillas. Journal of Segmentation in Marketing 2 (1): 5-18. https://doi.org/10.1300/ J142v02n01_02.

De Bruin, Tonia, Michael Rosemann, Ronald Freeze, and Uday Kaulkarni. 2005. Understanding the Main Phases of Developing a Maturity Assessment Model. In Australasian Conference on Information Systems (ACIS), ed. D. Bunker, B. Campbell, and J. Underwood, 8-19. Australasian Chapter of the Association for Information Systems. https://eprints.qut.edu.au/25152/.

Deszczyński, Bartosz. 2016a. The Impact of Opportunity Management on the Relationship Business Model (A Study in the Polish Housing Industry). Journal of Eastern European and Central Asian Research (JEECAR) 3 (2): 1-10. https://doi.org/10.15549/jeecar.v3i2.137.

-2016b. The Maturity of Corporate Relationship Management. Gospodarka Narodowa 283 (3): 73-104. https://doi.org/10.33119/GN/100777.

Dolata, Ulrich. 2017. Apple, Amazon, Google, Facebook, Microsoft: Market Concentration - Competition - Innovation Strategies, Working Paper. SOI Discussion Paper. https://www.econstor.eu/handle/10419/152249

du Toit, Gerard, and Maureen Burns. 2014. How Banks Can Turn the Tide of Customer Defection. American Banker, December 24. https://www.americanbanker.com/opinion/how-banks-can-turn-the-tide-of-customer-defection 
Dyer, Jeffrey H., and Harbir Singh. 1998. The Relational View: Cooperative Strategy and Sources of Interorganizational Competitive Advantage. The Academy of Management Review 23 (4): 660-679. https://doi. org/10.2307/259056.

Eshghi, Abdolreza, Dominique Haughton, and Heikki Topi. 2007. Determinants of Customer Loyalty in the Wireless Telecommunications Industry. Telecommunications Policy 31 (2): 93-106. https://doi.org/10.1016/j. telpol.2006.12.005.

Fiske, Alan Page. 1992. The Four Elementary Forms of Sociality: Framework for a Unified Theory of Social Relations. Psychological Review 99 (4): 689-723. https://doi.org/10.1037/0033-295X.99.4.689.

FitzPatrick, Mary, Richard J. Varey, Christian Grönroos, and Janet Davey. 2015. Relationality in the Service Logic of Value Creation. Journal of Services Marketing 29 (6/7): 463-471. https://doi.org/10.1108/JSM-01-20150038 .

Galvão, Marcella Brito, Raíssa Corrêa de Carvalho, Lucas Ambrósio Bezerra de Oliveira, and Denise Dumke de Medeiros. 2018. Customer Loyalty Approach Based on CRM for SMEs. Journal of Business \& Industrial Marketing, June 4. https://doi.org/10.1108/JBIM-07-2017-0166

Granovetter, Mark S. 1977. The Strength of Weak Ties. American Journal of Sociology 78 (6): 1360-1380. https://doi.org/10.1016/B978-0-12-442450$0.50025-0$.

Grönroos, Christian. 2017. Relationship Marketing Readiness: Theoretical Background and Measurement Directions. Journal of Services Marketing 31 (3): 218-225. https://doi.org/10.1108/JSM-02-2017-0056.

Hakanen, Taru, and Elina Jaakkola. 2012. Co-creating Customer-focused Solutions within Business Networks: A Service Perspective. Edited by Evert Gummesson, Cristina Mele, and Francesco Polese. Journal of Service Management 23 (4): 593-611. https://doi.org/10.1108/0956423 1211260431.

Haythornthwaite, Caroline. 2000. Online Personal Networks: Size, Composition and Media Use Among Distance Learners. New Media \& Society 2 (2): 195-226. https://doi.org/10.1177/14614440022225779.

- 2005. Social Networks and Internet Connectivity Effects. Information, Communication \& Society 8 (2): 125-147. https://doi.org/10.1080/ 13691180500146185.

Henderson, Conor M., Joshua T. Beck, and Robert W. Palmatier. 2011. Review of the Theoretical Underpinnings of Loyalty Programs. Journal of Consumer Psychology 21 (3): 256-276. https://doi.org/10.1016/j.jcps.2011.02.007.

Heskett, James L., Thomas O. Jones, Gary W. Loveman, W. Earl Sasser Jr, and Leonard A. Schlesinger. 2008a. Putting the Service-Profit Chain to Work. Harvard Business Review, July 1. https://hbr.org/2008/07/puttingthe-service-profit-chain-to-work 
Heskett, James L., W. Earl Sasser, and Joe Wheeler. 2008b. The Ownership Quotient: Putting the Service Profit Chain to Work for Unbeatable Competitive Advantage. Boston: Harvard Business Press.

Hibbert, Sally, Heidi Winklhofer, and Mohamed Sobhy Temerak. 2012. Customers as Resource Integrators: Toward a Model of Customer Learning. Journal of Service Research 15 (3): 247-261. https://doi.org/10.1177/10946705 12442805.

Hooks, Karen L., Steven E. Kaplan, Joseph J. Schultz Jr., and Lawrence A. Ponemon. 1994. Enhancing Communication to Assist in Fraud Prevention and Detection; Comment: Whistle-Blowing as an Internal Control Mechanism: Individual and Organizational Considerations. Auditing 13 (2): 86.

Hunt, Shelby D. 1997. Resource-Advantage Theory: An Evolutionary Theory of Competitive Firm Behavior? Journal of Economic Issues 31 (1): 59-78. https:// doi.org/10.1080/00213624.1997.11505891.

Hunt, Shelby D., and Robert M. Morgan. 1995. The Comparative Advantage Theory of Competition. Journal of Marketing 59 (2): 1-15. https://doi. org/10.2307/1252069.

- 1996. The Resource-Advantage Theory of Competition: Dynamics, Path Dependencies, and Evolutionary Dimensions. Journal of Marketing: 107-114.

- 2005. The Resource-Advantage Theory of Competition. In Review of Marketing Research 1: 153-206. Review of Marketing Research. Emerald Group Publishing Limited. https://doi.org/10.1108/S1548-6435(2004) 0000001008.

Kaplan, Robert, and Robin Cooper. 1998. Cost \& Effect: Using Integrated Cost Systems to Drive Profitability and Performance. Boston: Harvard Business Press.

Kegan, Robert, Lisa Lahey, Andy Fleming, and Matthew Miller. 2014. Making Business Personal. Harvard Business Review, April 1. https://hbr. org/2014/04/making-business-personal

Kotler, Philip, and Kevin Lane Keller. 2009. Marketing Management. Pearson Prentice Hall. https://books.google.pl/books?id=QiTOHgAACAAJ.

Krekel, Christian, George Ward, and Jean-Emmanuel De Neve. 2019. Employee Wellbeing, Productivity, and Firm Performance. Saïd Business School Research Papers 4: 1-43.

Ledbetter, Andrew M. 2010. Content- and Medium-Specific Decomposition of Friendship Relational Maintenance: Integrating Equity and Media Multiplexity Approaches. Journal of Social and Personal Relationships 27 (7): 938-955. https://doi.org/10.1177/0265407510376254.

Lepak, David P., Ken G. Smith, and M. Susan Taylor. 2007. Value Creation and Value Capture: A Multilevel Perspective. Academy of Management Review 32 (1): 180-194. https://doi.org/10.5465/amr.2007.23464011.

Lovelock, Christopher H. 1983. Classifying Services to Gain Strategic Marketing Insights. Journal of Marketing 47 (3): 9-20. https://doi. org/10.1177/002224298304700303. 
Lovelock, Christopher H., Paul Patterson, and Jochen Wirtz. 2014. Services Marketing. An Asia-Pacific and Australian Perspective. 6th ed. Melbourne: Pearson Australia. https://www.pearson.com.au/9781486002702.

Lusch, Robert F., and Stephen L. Vargo. 2014. Service-Dominant Logic: Premises, Perspectives, Possibilities. New York: Cambridge University Press.

Lusch, Robert F., Stephen L. Vargo, and Matthew O'Brien. 2007. Competing through Service: Insights from Service-Dominant Logic. Journal of Retailing, Service Excellence 83 (1): 5-18. https://doi.org/10.1016/j.jretai.2006.10.002.

Mayer, David M., Maribeth Kuenzi, and Rebecca L. Greenbaum. 2010. Examining the Link Between Ethical Leadership and Employee Misconduct: The Mediating Role of Ethical Climate. Journal of Business Ethics 95 (1): 7-16. https://doi.org/10.1007/s10551-011-0794-0.

Miles, Raymond E., Charles C. Snow, Alan D. Meyer, and Henry J. Coleman. 1978. Organizational Strategy, Structure, and Process. Academy of Management Review 3 (3): 546-562. https://doi.org/10.5465/amr.1978.4305755.

Montgomery, Cynthia A., and Birger Wernerfelt. 1988. Diversification, Ricardian Rents, and Tobin's q. The RAND Journal of Economics 19 (4): 623-632. https://doi.org/10.2307/2555461.

Morrison, Sharon, and Frederick G. Crane. 2007. Building the Service Brand by Creating and Managing an Emotional Brand Experience. Journal of Brand Management 14 (5): 410-421. https://doi.org/10.1057/palgrave. bm.2550080.

Mugge, Ruth, Jan P.L. Schoormans, and Hendrik N.J. Schifferstein. 2005. Design Strategies to Postpone Consumers' Product Replacement: The Value of a Strong Person-Product Relationship. The Design Journal 8 (2): 38-48. https:// doi.org/10.2752/146069205789331637.

Olson, Eric M., F. Stanley, G. Slater, Tomas M. Hult, and Kai M. Olson. 2018. The Application of Human Resource Management Policies within the Marketing Organization: The Impact on Business and Marketing Strategy Implementation. Industrial Marketing Management 69: 62-73. https://doi. org/10.1016/j.indmarman.2018.01.029.

Palmatier, Robert W., Rajiv P. Dant, and Dhruv Grewal. 2007. A Comparative Longitudinal Analysis of Theoretical Perspectives of Interorganizational Relationship Performance. Journal of Marketing 71 (4): 172-194. https:// doi.org/10.1509/jmkg.71.4.172.

Palmatier, Robert W., Cheryl Burke Jarvis, Jennifer R. Bechkoff, and Frank R. Kardes. 2009. The Role of Customer Gratitude in Relationship Marketing. Journal of Marketing 73 (5): 1-18. https://doi.org/10.1509/jmkg.73.5.1.

Parasuraman, A. 1988. Servqual: A Multiple-Item Scale for Measuring Consumer Perc. Journal of Retailing; Greenwich 64 (1, Spring): 12.

Parasuraman, A., Valarie A. Zeithaml, and Leonard L. Berry. 1985. A Conceptual Model of Service Quality and Its Implications for Future Research. Journal of Marketing 49 (4): 41-50. https://doi.org/10.1177/002224298504900403. 
Parasuraman, A., Leonard L. Berry, and Valarie A. Zeithaml. 1991. Refinement and Reassessment of the SERVQUAL Scale. Journal of Retailing; Greenwich 67 (4, Winter): 420.

Pavitt, Keith. 1990. What We Know About the Strategic Management of Technology. California Management Review 32 (3): 17.

Payne, Adrian, and Pennie Frow. 2013. Strategic Customer Management: Integrating Relationship Marketing and CRM. Cambridge University Press.

Pervan, Simon J., Liliana L. Bove, and Lester W. Johnson. 2009. Reciprocity as a Key Stabilizing Norm of Interpersonal Marketing Relationships: Scale Development and Validation. Industrial Marketing Management 38 (1): 60-70. https://doi.org/10.1016/j.indmarman.2007.11.001.

Peteraf, Margaret A. 1993. The Cornerstones of Competitive Advantage: A Resource-Based View. Strategic Management Journal 14 (3): 179-191. https://doi.org/10.1002/smj.4250140303.

Pollack, David M., and Leslie J. Pollack. 1996. Using $360^{\circ}$ Feedback in Performance Appraisal. Public Personnel Management; Thousand Oaks 25 (4): 507-528. https://doi.org/10.1177/009102609602500410.

Polskie, Radio. 2014. Przeciętny Polak Przeprowadza Się Raz Na 15 Lat. https:// www.polskieradio24.pl/42/259/Artykul/1075300,PrzecietnyPolak-przeprowadza-sie-raz-na-15-lat

Porter, Michael E. 1979. How Competitive Forces Shape Strategy. Harvard Business Review, March 1. https://hbr.org/1979/03/how-competitiveforces-shape-strategy

Reichheld, Frederick. 2003. The One Number You Need to Grow. Harvard Business Review, December: 1-11.

Reichheld, Frederick, and Rob Markey. 2011. The Ultimate Question 2.0: How Net Promoter Companies Thrive in a Customer. Boston: Harvard Business Publishing. https://books.google.pl/books?hl=pl\&lr=\&id=e8jhiYjQrU0C\&o $\mathrm{i}=$ fnd \&pg $=$ PR7 \& dq = reichheld + markey \&ots $=C C$ C eQacr8I\&sig $=i S g h$ IWq6TPhrVgOpVEfeP3Hnzw\&redir_esc =y\#v=onepage \&q=reichheld $\% 20$ markey\&f=false.

Reichheld, Frederik, and Thomas Teal. 2001. The Loyalty Effect: The Hidden Force Behind Growth, Profits, and Lasting Value, Loyalty-Based Management. Boston: Harvard Business School Press. https://books.google.pl/ books?id=D-JlUoXtf-AC.

Robinson, Jennifer. 2008. How The Ritz-Carlton Manages the Mystique. Gallup. com, December 11. https://news.gallup.com/businessjournal/112906/ How-RitzCarlton-Manages-Mystique.aspx

Romanowska, Maria. 2014. Bariery Efektywności Badań Naukowych z Zakresu Zarządzania Strategicznego. Prace Naukowe Watbrzyskiej Wy̌eszej Szkoty Przedsiębiorczósci i Zarządzania 27 (2): 101-108. 
Rossiter, John, and Steve Bellman. 2012. Emotional Branding Pays Off: How Brands Meet Share of Requirements Through Bonding, Companionship, and Love. Journal of Advertising Research 52 (3): 29l-296. https://doi. org/10.2501/JAR-52-3-291-296.

Rumelt, Richard P., D. Schendel, and David J. Teece. 1995. Fundamental Issues in Strategy: A Research Agenda. Cambridge, MA: Harvard Business School Press. https://books.google.pl/books?id=rttTzECN9_YC.

Sasser, W. Earl, Leonard A. Schlesinger, and James L. Heskett. 1997. Service Profit Chain. New York: Simon and Schuster.

Schmidt-Subramanian, Maxi. 2019. Forrester Publishes NPS Benchmarks For 260 Brands In 16 Industries. Forrester Blogs (blog), November 7. https://go.forrester.com/blogs/nps-benchmarks/.

Schumann, Jan H., Florian v. Wangenheim, Anne Stringfellow, Zhilin Yang, Sandra Praxmarer, Fernando R. Jiménez, Vera Blazevic, Randall M. Shannon, G. Shainesh, and Marcin Komor. 2010. Drivers of Trust in Relational Service Exchange: Understanding the Importance of Cross-Cultural Differences. Journal of Service Research 13 (4): 453-468. https://doi. org/10.1177/1094670510368425.

Shostack, Lynn G. 1982. How to Design a Service. European Journal of Marketing 16 (1): 49-63. https://doi.org/10.1108/EUM0000000004799.

Slater, Stanley F., and Eric M. Olson. 2001. Marketing's Contribution to the Implementation of Business Strategy: An Empirical Analysis. Strategic Management Journal 22 (11): 1055-1067. https://doi.org/10.1002/ smj. 198.

Slater, Stanley F., Eric M. Olson, and Carol Finnegan. 2011. Business Strategy, Marketing Organization Culture, and Performance. Marketing Letters 22 (3): 227-242. https://doi.org/10.1007/s11002-010-9122-1.

Stankiewicz, Marek J. 2000. Substance and Methods of Evaluation of Enterprise Competitiveness. Gospodarka Narodowa. The Polish Journal of Economics 161 (7-8): 95-111. https://doi.org/10.33119/GN/113968.

Teece, David J. 1982. Towards an Economic Theory of the Multiproduct Firm. Journal of Economic Behavior \& Organization 3 (1): 39-63. https://doi. org/10.1016/0167-2681(82)90003-8.

- 1984. Economic Analysis and Strategic Management. California Management Review (Pre-1986); Berkeley 26 (3, Spring): 87.

Uncles, Mark D., Grahame R. Dowling, and Kathy Hammond. 2003. Customer Loyalty and Customer Loyalty Programs. Journal of Consumer Marketing 20 (4): 294-316. https://doi.org/10.1108/07363760310483676.

Varelius, Jukka. 2009. Is Whistle-Blowing Compatible with Employee Loyalty? Journal of Business Ethics 85 (2): 263-275.

Vargo, Stephen L., Josina Vink, and Kaisa Koskela-Huotari. 2020. ServiceDominant Logic: Foundations and Applications. In The Routledge Handbook of Service Research Insights and Ideas, ed. E. Bridges and K. Fowler, 3-23. New York: 
Routledge. https://www.researchgate.net/profile/Kaisa_Koskela-Huotari/ publication/340777398_Service-Dominant_Logic_Foundations_and_ Applications/links/5e9d3f099285lc2f52b288fc/Service-Dominant-LogicFoundations-and-Applications.pdf.

Walker, Orville C., and Robert W. Ruekert. 1987. Marketing's Role in the Implementation of Business Strategies: A Critical Review and Conceptual Framework. Journal of Marketing 51 (3): 15-33. https://doi. org/10.1177/002224298705100302.

Williamson, Oliver E. 1991. Strategizing, Economizing, and Economic Organization. Strategic Management Journal 12 (S2): 75-94. https://doi. org/10.1002/smj.4250121007.

Wirtz, Jochen, and Christopher H. Lovelock. 2016. Services Marketing: People, Technology, Strategy. 8th ed. Hackensack: World Scientific Publishing Company. Wirtz, Jochen, Siok Kuan Tambyah, and Anna S. Mattila. 2010. Organizational Learning from Customer Feedback Received by Service Employees: A Social Capital Perspective. Journal of Service Management 21 (3): 363-387. https:// doi.org/10.1108/09564231011050814.

Wood, Wendy, and David T. Neal. 2009. The Habitual Consumer. Journal of Consumer Psychology 19 (4): 579-592. https://doi.org/10.1016/j. jcps.2009.08.003.

Zhang, Mingli, Lingyun Guo, Mu Hu, and Wenhua Liu. 2017. Influence of Customer Engagement with Company Social Networks on Stickiness: Mediating Effect of Customer Value Creation. International Journal of Information Management 37 (3): 229-240. https://doi.org/10.1016/j. ijinfomgt.2016.04.010.

Open Access This chapter is licensed under the terms of the Creative Commons Attribution 4.0 International License (http://creativecommons.org/licenses/ by $/ 4.0 /$ ), which permits use, sharing, adaptation, distribution and reproduction in any medium or format, as long as you give appropriate credit to the original author(s) and the source, provide a link to the Creative Commons licence and indicate if changes were made.

The images or other third party material in this chapter are included in the chapter's Creative Commons licence, unless indicated otherwise in a credit line to the material. If material is not included in the chapter's Creative Commons licence and your intended use is not permitted by statutory regulation or exceeds the permitted use, you will need to obtain permission directly from the copyright holder.

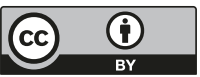

